\title{
Antarctic climate variability on regional and continental scales over the last 2000 years
}

\author{
Barbara Stenni $^{1,2}$, Mark A. J. Curran ${ }^{3,4}$, Nerilie J. Abram ${ }^{5,6}$, Anais Orsi ${ }^{7}$, Sentia Goursaud ${ }^{7,8}$, \\ Valerie Masson-Delmotte ${ }^{7}$, Raphael Neukom ${ }^{9}$, Hugues Goosse ${ }^{10}$, Dmitry Divine ${ }^{11,12}$, Tas van Ommen ${ }^{3,4}$, \\ Eric J. Steig ${ }^{13}$, Daniel A. Dixon ${ }^{14}$, Elizabeth R. Thomas ${ }^{15}$, Nancy A. N. Bertler ${ }^{16,17}$, Elisabeth Isaksson ${ }^{11}$, \\ Alexey Ekaykin ${ }^{18,19}$, Martin Werner ${ }^{20}$, and Massimo Frezzotti ${ }^{21}$ \\ ${ }^{1}$ Department of Environmental Sciences, Informatics and Statistics, Ca' Foscari University of Venice, Venice, Italy \\ ${ }^{2}$ Institute for the Dynamics of Environmental Processes, CNR, Venice, Italy \\ ${ }^{3}$ Australian Antarctic Division, 203 Channel Highway, Kingston, Tasmania 7050, Australia \\ ${ }^{4}$ Antarctic Climate \& Ecosystems Cooperative Research Centre, University of Tasmania, Hobart 7001, Australia \\ ${ }^{5}$ Research School of Earth Sciences, Australian National University, Canberra ACT 2601, Australia \\ ${ }^{6}$ ARC Centre of Excellence for Climate System Science, Australian National University, Canberra ACT 2601, Australia \\ ${ }^{7}$ Laboratoire des Sciences du Climat et de 1'Environnement (IPSL/CEA-CNRS-UVSQ UMR 8212), CEA Saclay, \\ 91191 Gif-sur-Yvette CEDEX, France \\ ${ }^{8}$ Université Grenoble Alpes, Laboratoire de Glaciologie et Géophysique de l'Environnement (LGGE), \\ 38041 Grenoble, France \\ ${ }^{9}$ University of Bern, Oeschger Centre for Climate Change Research \& Institute of Geography, 3012 Bern, Switzerland \\ ${ }^{10}$ Université catholique de Louvain, Earth and Life Institute, Centre de recherches sur la terre et le climat Georges Lemaître, \\ 1348 Louvain-la-Neuve, Belgium \\ ${ }^{11}$ Norwegian Polar Institute, Fram Centre, 9296 Troms $\varnothing$, Norway \\ ${ }^{12}$ Department of Mathematics and Statistics, Faculty of Science, University of Troms $\emptyset$ - The Arctic University of Norway, \\ 9037, Tromsø, Norway \\ ${ }^{13}$ Department of Earth and Space Sciences, University of Washington, Seattle, WA 98195, USA \\ ${ }^{14}$ Climate Change Institute, University of Maine, Orono, ME 04469, USA \\ ${ }^{15}$ British Antarctic Survey, Cambridge, CB3 0ET, UK \\ ${ }^{16}$ Antarctic Research Centre, Victoria University of Wellington, Wellington 6012, New Zealand \\ ${ }^{17}$ National Ice Core Research Facility, GNS Science, Gracefield 5040, New Zealand \\ ${ }^{18}$ Arctic and Antarctic Research Institute, St. Petersburg, Russia \\ ${ }^{19}$ Institute of Earth Sciences, Saint Petersburg State University, St. Petersburg, Russia \\ ${ }^{20}$ Alfred Wegener Institute, Helmholtz Centre for Polar and Marine Research, 27570 Bremerhaven, Germany \\ ${ }^{21}$ ENEA Casaccia, Rome, Italy
}

Correspondence to: Barbara Stenni (barbara.stenni@unive.it)

Received: 28 February 2017 - Discussion started: 22 March 2017

Revised: 15 September 2017 - Accepted: 20 September 2017 - Published: 17 November 2017 
Abstract. Climate trends in the Antarctic region remain poorly characterized, owing to the brevity and scarcity of direct climate observations and the large magnitude of interannual to decadal-scale climate variability. Here, within the framework of the PAGES Antarctica2k working group, we build an enlarged database of ice core water stable isotope records from Antarctica, consisting of 112 records. We produce both unweighted and weighted isotopic $\left(\delta^{18} \mathrm{O}\right)$ composites and temperature reconstructions since $0 \mathrm{CE}$, binned at 5- and 10-year resolution, for seven climatically distinct regions covering the Antarctic continent. Following earlier work of the Antarctica2k working group, we also produce composites and reconstructions for the broader regions of East Antarctica, West Antarctica and the whole continent. We use three methods for our temperature reconstructions: (i) a temperature scaling based on the $\delta^{18} \mathrm{O}$-temperature relationship output from an ECHAM5-wiso model simulation nudged to ERA-Interim atmospheric reanalyses from 1979 to 2013, and adjusted for the West Antarctic Ice Sheet region to borehole temperature data, (ii) a temperature scaling of the isotopic normalized anomalies to the variance of the regional reanalysis temperature and (iii) a composite-plusscaling approach used in a previous continent-scale reconstruction of Antarctic temperature since $1 \mathrm{CE}$ but applied to the new Antarctic ice core database. Our new reconstructions confirm a significant cooling trend from 0 to $1900 \mathrm{CE}$ across all Antarctic regions where records extend back into the 1st millennium, with the exception of the Wilkes Land coast and Weddell Sea coast regions. Within this long-term cooling trend from 0 to $1900 \mathrm{CE}$, we find that the warmest period occurs between 300 and $1000 \mathrm{CE}$, and the coldest interval occurs from 1200 to 1900 CE. Since 1900 CE, significant warming trends are identified for the West Antarctic Ice Sheet, the Dronning Maud Land coast and the Antarctic Peninsula regions, and these trends are robust across the distribution of records that contribute to the unweighted isotopic composites and also significant in the weighted temperature reconstructions. Only for the Antarctic Peninsula is this most recent century-scale trend unusual in the context of natural variability over the last 2000 years. However, projected warming of the Antarctic continent during the 21 st century may soon see significant and unusual warming develop across other parts of the Antarctic continent. The extended Antarctica2k ice core isotope database developed by this working group opens up many avenues for developing a deeper understanding of the response of Antarctic climate to natural and anthropogenic climate forcings. The first long-term quantification of regional climate in Antarctica presented herein is a basis for data-model comparison and assessments of past, present and future driving factors of Antarctic climate.

\section{Introduction}

Antarctica is the region of the world where instrumental climate records are shortest and sparsest. Estimates of temperature change with reasonable coverage across the full Antarctic continent are only available since $1958 \mathrm{CE}$ (Nicolas and Bromwich, 2014), and the large magnitude of year-to-year climate variability that characterizes Antarctica makes the interpretation of trends in this data-sparse region problematic (Jones et al., 2016). As a result, the knowledge of past Antarctic temperature and climate variability is predominantly dependent on proxy records from natural archives. While coastal proxy records are being developed from terrestrial and marine archives, information on Antarctic climate above the ice sheet exclusively relies on the climatic interpretation of ice core records.

Within the variety of measurements performed in boreholes and ice cores, only water stable isotopes can provide subdecadal-resolution records of past temperature changes (Küttel et al., 2012). In high-accumulation areas of coastal zones and West Antarctica, annual layer counting is feasible during the last centuries to millennia (Plummer et al., 2012; Abram et al., 2013; Thomas et al., 2013; Sigl et al., 2016; Winstrup et al., 2017, under review), and annual water stable isotope signals can be delivered. However, in the dry regions of the central Antarctic plateau, where the longest ice core records are available, chronologies are less accurate and rely on the identification of volcanic deposits that can be used to tie ice cores from different sites to a common Antarctic ice core age scale (Sigl et al., 2014, 2015).

The chemical and physical signals measured in an individual ice core reflect a local climatic signal archived through the deposition and reworking of snow layers. The intermittency of Antarctic precipitation (Masson-Delmotte et al., 2011; Sime et al., 2009), variability in precipitation source regions (Sodemann and Stohl, 2009), and post-depositional effects of snow layers including wind drift and scouring, sublimation, and snow metamorphism (Frezzotti et al., 2007; Ekaykin et al., 2014; Touzeau et al., 2016; Casado et al., 2016; Hoshina et al., 2014; Steen-Larsen et al., 2014) can distort the climate signal preserved within ice cores and produces non-climatic noise. As a result, obtaining a robust climate signal can only be achieved through the combination of multiple ice core records from a given site and/or region, and through the site-specific calibration of the relationships between water stable isotopes and temperature.

Water can be characterized by the stable isotope ratios of oxygen $\left(\delta^{18} \mathrm{O}\right.$ : the deviation of the ratio of ${ }^{18} \mathrm{O} /{ }^{16} \mathrm{O}$ in a sample, relative to that of the standard, Vienna Standard Mean Ocean Water) and of hydrogen $(\delta D$ : the deviation of the ratio of ${ }^{2} \mathrm{H} /{ }^{1} \mathrm{H}$ ). Both of these parameters within ice cores provide information on past temperatures. There is solid theoretical understanding of distillation processes relating moisture transport towards the polar regions with air mass cooling and the progressive loss of heavy water molecules along 
the condensation pathway (Jouzel and Merlivat, 1984). This theoretical understanding is further supported by numerical modelling performed using atmospheric general circulation models equipped with water stable isotopes (Jouzel, 2014). The effects of these processes are observed in the spatial relationships between the isotopic composition of Antarctic precipitation and surface snow and surface air temperature across the continent. However, relationships between water stable isotopes in snow and surface temperature may vary through time as a result of changes between condensation and surface temperature (in relation to changes in boundary layer stability), changes in moisture origin and initial evaporation conditions, changes in atmospheric transport pathways, and changes in precipitation seasonality or intermittency (Masson-Delmotte et al., 2008). Investigations based on the sampling of Antarctic precipitation have demonstrated that seasonal and inter-annual isotope vs. temperature slopes are generally smaller than spatially derived relationships (van Ommen and Morgan, 1997; Schneider et al., 2005; Stenni et al., 2016; Schlosser et al., 2004; Ekaykin et al., 2004; Fernandoy et al., 2010). Moreover, emerging studies combining the monitoring of surface water vapour isotopic composition with the isotopic composition retained in surface snow and precipitation have revealed that snow-air isotopic exchanges during snow metamorphism affect surface snow isotopic composition (Ritter et al., 2016; Casado et al., 2016; Touzeau et al., 2016). It is not yet possible to assess the importance of such post-deposition processes for the interpretation of ice core water stable isotope records, but they may enhance the relationship between snow isotopic composition and surface temperature more than expected from the intermittency of snowfall (Touzeau et al., 2016). Changes in ice sheet height due to ice dynamics may also affect the surface climate trends inferred from water stable isotope records; however, this influence should be of second order over the last 2000 year interval that is the focus of this study (Fegyveresi et al., 2011).

As a result, the two key challenges to reconstruct past changes in Antarctic temperature from ice core isotope records are (1) to develop methodologies to combine different individual or stacked ice core records in order to deliver regional-scale climate signals and (2) to quantify the temperature changes represented by water stable isotope variations.

Goosse et al. (2012) first calculated a composite of Antarctic temperature simply by averaging seven standardized temperature records inferred from water stable isotopes using a spatial isotope-temperature relationship for the last millennium. The first coordinated effort to reconstruct Antarctic temperature during the last 2000 years (PAGES 2k Consortium, 2013) screened published ice core records for annual layer counting or alignment of volcanic sulfate records and overlap with instrumental temperature data (Steig et al., 2009), leading to the selection of 11 records. The reconstruction procedure used a composite-plus-scaling (CPS) approach similar to the methodology of Schneider et al. (2006) and produced reconstructions of the continent-wide temperature history as well as specific West Antarctica and East Antarctica reconstructions. The skill of the reconstructions was limited by the number of available records through time (for instance, only one predictor in each region prior to $166 \mathrm{CE})$. This analysis identified significant $(p<0.01)$ cooling trends from 166 to $1900 \mathrm{CE}, 2.5$ times larger in West Antarctica than in East Antarctica. A robust cooling trend over this time period has also been identified from terrestrial and marine reconstructions from other regions (PAGES $2 \mathrm{k}$ Consortium, 2013; McGregor et al., 2015).

The comparison of these first Antarctic 2k time series with those from other regions obtained within the PAGES $2 \mathrm{k}$ working groups identified three specificities: (i) reconstructed Antarctic centennial variations did not correlate with those from other regions, (ii) the Antarctic region was the only one where a protracted cold period did not start around $1580 \mathrm{CE}$ (iii) the Antarctic region was the only one where the 20th century was not the warmest century of the last 2000 years. A recent effort to characterize Antarctic and subAntarctic climate variability during the last 200 years also concluded that most of the trends observed since satellite climate monitoring began in 1979 CE cannot yet be distinguished from natural (unforced) climate variability (Jones et al., 2016), and observed instrumental climate trends are of the opposite sign to those produced by most forced climate model simulations over the same post-1979 CE interval. The only exception to this conclusion was for changes in the Southern Annular Mode (SAM), the leading mode of atmospheric circulation variability in the high latitudes of the Southern Hemisphere ( $\mathrm{SH}$ ), which has showed a significant and unusual positive trend since $1979 \mathrm{CE}$.

While changes in the SAM have been related to the human influence on stratospheric ozone and greenhouse gases (Thompson et al., 2011), major gaps remain in identifying the drivers of multi-centennial Antarctic climate variability. For instance, the influence of solar and volcanic forcing on Antarctic climate variability remains unclear. This is due to both the lack of observations and to the lack of confidence in climate model skill for the Antarctic region (Flato et al., 2013). Goosse et al. (2012) have used simulations from an intermediate complexity model to attribute the Antarctic annual mean cooling trend from 850 to $1850 \mathrm{CE}$ to volcanic forcing. Recent comparisons of climate model simulations with the PAGES $2 \mathrm{k}$ regional reconstructions have highlighted greater model-data disagreement in the $\mathrm{SH}$ than in the Northern Hemisphere (PAGES 2k-PMIP3 group, 2015; Abram et al., 2016); such disagreement could be due either to model deficiencies or to large uncertainties in the reconstructions, which were built on relatively small number of records. Changes in ocean heat content and ocean heat transport have likely contributed to the different temperature evolution at high southern latitudes compared to other regions of the Earth (Goosse, 2017), and model-based studies have suggested that circulation in the Southern Ocean 
may act to delay, by centuries, the development of sustained warming trends in high southern latitudes (Armour et al., 2016). Antarctic temperature reconstructions spanning the last 2000 years may help to better constrain the processes and timescales by which natural and anthropogenic forcing act to affect climate changes in the Antarctic region.

This motivates our efforts to produce updated Antarctic temperature reconstructions. The previous continent-scale reconstruction (PAGES 2k Consortium, 2013), in which only a limited number of records have been used, may mask important regional-scale features of Antarctica's climate evolution. Here we use an expanded paleoclimate database of Antarctic ice core isotope records and new reconstruction methodologies to reconstruct the climate of the past 2000 years, on a decadal scale and regional basis. Seven distinct climatic regions have been selected: the Antarctic Peninsula, the West Antarctic Ice Sheet (WAIS), the East Antarctic Plateau and four coastal domains of East Antarctica. This regional selection, which is supported by regional atmospheric RACMO2.3p2 model results (Thomas et al., 2017; Van Wessem et al., 2014), is applied to both Antarctic ice-core-derived isotopic (temperature proxy) and snow accumulation rate reconstructions (see companion paper in the same issue by Thomas et al.). Section 2 describes the ice core and the temperature data sets used in this study, as well as the modelling framework used to support the analysis. The climate region definition, the preprocessing of the data and the different reconstruction methods are presented in Sect. 3. Section 4 discusses our new regional isotopic and temperature reconstructions for Antarctica, including the application of the previous methodology to the new database. Finally, Sect. 5 presents the summary of our results and their implications.

\section{Data sets}

\subsection{Ice core records}

Here we present and use a new expanded database that has been compiled in the framework of the PAGES Antarctica2k working group. The initial selection criteria are those requested by the PAGES $2 \mathrm{k}$ network (http://www. pages-igbp.org/ini/wg/2k-network/data) for the building of the community-sourced database of temperature-sensitive proxy records (PAGES 2k Consortium, 2017). Briefly, (i) the records must be publicly available and published, (ii) a relation between the climate proxies and variables should be stated, (iii) the record duration should be between 300 and 2000 years, (iv) the chronology, certified by the data owner, should contain at least one chronological control point near the end (most recent) part of the record and another near the oldest part of the record and (v) the resolution should be at least one analysis every 50 years.

In building the Antarctica2k database we also allow shorter records to be included, although we request a strati- graphic control using volcanic markers (Sigl et al., 2014) and, whenever possible, a dating by annual layer counted chronology. This last requirement is only possible in the high-accumulation regions of West Antarctica, the Antarctic Peninsula and coastal areas of East Antarctica. The inclusion of shorter records is designed to improve data coverage for assessments of climatic trends in Antarctica during the past century. The 11 records included in the previous continentscale reconstruction (PAGES 2k Consortium, 2013) relied on a highly precise chronological framework consisting of a common chronology, which used 42 volcanic events to synchronize the records. Here, we use both high- and lowresolution records. Most of the records have a data resolution ranging from 0.025 to 5 years (only three records have a resolution of $>10$ years). Previous studies (Frezzotti et al., 2007; Ekaykin et al., 2014) have shown that post-depositional and wind scouring effects, acting more effectively when the accumulation rate is very low, limit our ability to obtain temperature reconstructions at annual resolution in most of the interior of Antarctica. Because of this, in our regional reconstructions we use 5-year-averaged data for reconstructing the last 200 years, and 10-year averages for reconstructing the last 2000 years. Using 5- or 10-year averages also decreases our dependence on an annually precise chronological constraint between the ice core records, allowing us to more confidently use the expanded database. The data have been also screened for glaciological problems, with those records that are very likely to be affected by ice flow dynamics excluded.

This enlarged database consists of 112 isotopic records. A list of the records used are reported in Table S1 (in the Supplement) and their spatial distribution is shown in Fig. 1. Figure S1 shows the location of the ice core sites along with a visualization of the record lengths. Most of the records of this new database cover the last 200 years and this is particularly true for the more coastal areas. Within the database, 36 records cover just the last 50 years or less, while 50 records cover the whole length of the past 200 years. There are 15 records that cover the last 1000 years, while only nine records reach as far back as $0 \mathrm{CE}$.

\subsection{Temperature product}

The instrumental record is very short in Antarctica, and most ice core sites do not have weather station measurements associated with the cores. In addition, the retrieval of the first metre of firn can be difficult, due to poor cohesion of the snow. As a result, for many sites, there is no overlap between instrumental and proxy data, which complicates the proxy calibration exercise. To enlarge the calibration data set, we use the climate field reconstruction from Nicolas and Bromwich (2014) (hereafter NB2014; http://polarmet.osu.edu/datasets/ Antarctic_recon/). This surface temperature data set provides homogeneous data at $60 \mathrm{~km}$ resolution, extends from 1957 to 2013 and includes the revised Byrd temperature record (Bromwich et al., 2013) that improves the skill of the tem- 

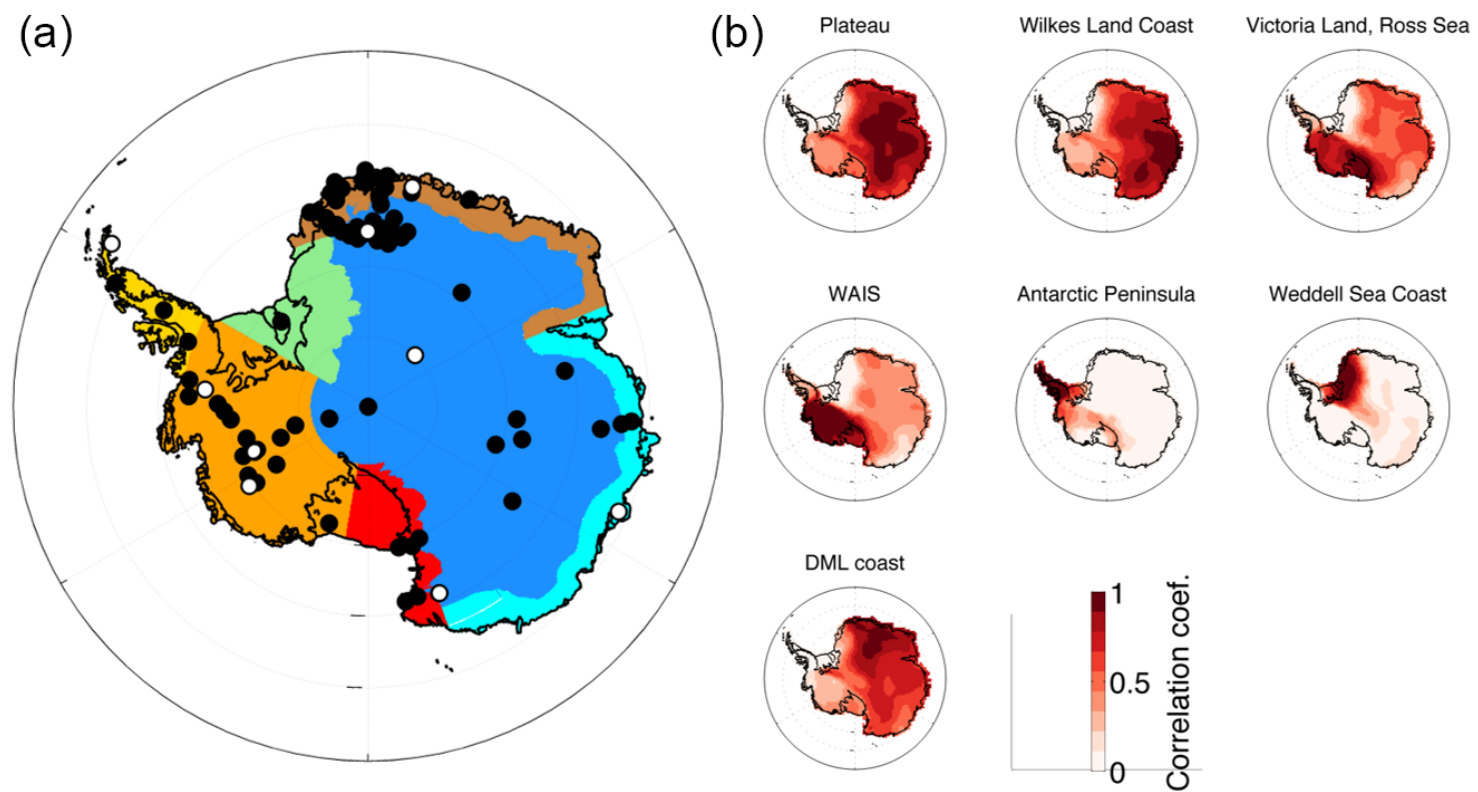

Figure 1. (a) Schematic map of the seven Antarctic regions selected for the regional reconstructions. In blue is the East Antarctic Plateau, in light blue the Wilkes Land Coast, in green the Weddell Sea Coast, in yellow the Antarctic Peninsula, in orange the West Antarctic Ice Sheet, in red the Victoria Land Coast-Ross Sea and in brown the Dronning Maud Land Coast. The dots show the site locations. The white dots represent the sites that have been used in the previous continent-scale reconstruction (PAGES 2k Consortium, 2013). (b) Correlation maps between the regional mean temperature and each grid point using the Nicolas and Bromwich (2014) data set.

perature product over West Antarctica. It covers a longer time span than reliable atmospheric reanalysis products for Antarctica (which begin only in 1979 CE) and has a higher spatial resolution than available isotope-enabled general circulation model (GCM) outputs. This data set is used to estimate the spatial representativeness of individual core sites (Sect. 3.3.2), to scale the normalized isotopic anomaly data to temperature (Sect. 3.4.2) and to calculate the surface temperature reconstructions with the CPS method (Sect. 3.4.4).

\subsection{Modelling framework}

In order to use model information on isotope-temperature relationships in Antarctic precipitation, we use a reference simulation performed using the general atmospheric circulation model ECHAM5-wiso. The initial ECHAM5 model (Roeckner et al., 2003) has been equipped with water stable isotopes (Werner et al., 2011), following earlier work on ECHAM3 (Hoffmann et al., 1998) and ECHAM4 (Werner et al., 2001), and accounting for fractionation processes during phase changes. This model is used here because recent studies, based on model-data comparisons using observations of precipitation and surface vapour isotopic composition on a global scale and in the Arctic (e.g. Werner et al., 2011; Steen-Larsen et al., 2017) have shown strong model skill of ECHAM5-wiso when it is run in high resolution as in this study (T106, with a mean horizontal grid resolution of approximately $1.1^{\circ} \times 1.1^{\circ}$ ). A study of the
2012 atmospheric river event in Greenland has demonstrated the skill of ECHAM5-wiso to reproduce these events, with a good representation of the water isotope signature (Bonne et al., 2014). In Antarctica, model performance was assessed against a compilation of surface data (Masson-Delmotte et al., 2008) and recent measurements of vapour and precipitation (Ritter et al., 2016; Dittmann et al., 2016).

Here, we use a 1958-2014CE simulation in which ECHAM5-wiso was nudged to atmospheric reanalyses from ERA-40 (Uppala et al., 2005) and ERA-Interim (Dee et al., 2011) and run using the same ocean surface boundary conditions (sea surface temperature and sea ice) as in ERA-40 and ERA-Interim. Ocean surface water isotopic values were set to constant values using a compilation of observational data (Schmidt et al., 2007). Inter-comparisons of reanalysis products showed good skills of ERA-Interim for Antarctic precipitation (Wang et al., 2016), surface temperature, and vertical profiles of winds and temperatures. However, comparisons with in situ observations reveal an underestimate of precipitation and a slight cold bias in the surface temperatures in some regions (Thomas and Bracegirdle, 2015).

The ECHAM5-wiso simulations produce a large increase, which is not observed in instrumental or ice core data, in the temperature and the $\delta^{18} \mathrm{O}$ outputs prior to 1979 (Goursaud et al., 2017). This arises from a discontinuity in the ERA40 reanalyses due to the lack of observations available for assimilation and boundary conditions prior to the satellite era (e.g. Antarctic sea ice) (Nicholas and Bromwich, 2014). We 
therefore use the ECHAM5-wiso simulations only for 19792013 CE.

For the analysis of the isotope-temperature relationships at each individual ice core site, we extracted the grid point data closest to each site. For the analysis of isotope relationships on a regional scale, we calculated the area-weighted average of model outputs at grid points within the region. The $\delta^{18} \mathrm{O}$-temperature relationship was calculated using the annual or seasonal average $2 \mathrm{~m}$ temperature and annual precipitation-weighted $\delta^{18} \mathrm{O}$, to mimic deposition processes. The simulation does not account for post-deposition processes (i.e. diffusion, which is not important on the 5- and 10-year timescales considered here; e.g. Küttel et al., 2012).

\section{Methodology}

\subsection{Defining climatic regions}

Earlier work of the PAGES Antarctica2k working group produced a continent-scale temperature reconstruction for the whole of Antarctica, as well as reconstructions for East and West Antarctica based on a separation approximated by the Transantarctic Mountains (PAGES 2k Consortium, 2013). These broad-scale groupings mask important regional climatic trends noted in individual studies. In particular, the absence of recent significant warming in the Antarctica $2 \mathrm{k}$ continent-scale temperature reconstruction is known to not be representative of all Antarctic locations (e.g. Steig et al., 2009, 2013; Mulvaney et al., 2012; Abram et al., 2013).

In this study, we choose seven climatic reconstruction regions (Fig. 1). These regions are defined based on our knowledge of regional climate and snow deposition processes in the Antarctic region, as well as the availability of ice core isotope records. In particular, we separated coastal regions (below $2000 \mathrm{~m}$ altitude) from the East Antarctic Plateau: coastal sites receive moisture from the high-latitude Southern Ocean and are affected by the nearby sea ice cover (Masson-Delmotte et al., 2008). In contrast, high-altitude sites receive moisture that has travelled at higher altitude, originating from further afield, and from clear sky precipitation (Ekaykin et al., 2004). The regional selections were further validated and refined by spatial correlation of temperature using the NB2014 data product. The seven climatic regions are defined as follows (see Table S1):

1. For East Antarctic Plateau, all East Antarctic contiguous regions are at an elevation higher than $2000 \mathrm{~m}$, including everything south of $85^{\circ} \mathrm{S}$. We exclude high peaks of the Transantarctic Mountains if they belong to the Victoria Land-Ross Sea coast (e.g. Taylor Dome or Hercules Névé).

2. Wilkes Land Coast sits at an altitude $<2000 \mathrm{~m}$ and extends from Lambert Glacier $\left(67^{\circ} \mathrm{E}\right)$ east to the start of Victoria Land and the Transantarctic Mountains $\left(160^{\circ} \mathrm{E}\right)$.
3. Weddell Sea Coast extends eastward from longitude 60 to $30^{\circ} \mathrm{W}$, and south of $75^{\circ} \mathrm{S}$, and lies at an altitude $<2000 \mathrm{~m}$. Eastward of the $30^{\circ} \mathrm{W}$ longitude, the $75^{\circ} \mathrm{S}$ latitude defines the boundary with the Dronning Maud Land coast region, with the northeastern corner of the Weddell Sea Coast region occurring where the $75^{\circ} \mathrm{S}$ latitude meets the $2000 \mathrm{~m}$ elevation contour. This region includes the Filchner Ice Shelf and most of the Ronne Ice Shelf.

4. Antarctic Peninsula encompasses the mountainous Antarctic Peninsula. Between 74 and $70^{\circ} \mathrm{S}$ the longitudinal boundaries lie between 60 and $80^{\circ} \mathrm{W}$, while north of $70^{\circ} \mathrm{S}$ the longitudinal boundaries increase to $50-$ $80^{\circ} \mathrm{W}$ so as to capture the northern end of the peninsula.

5. West Antarctic Ice Sheet is bounded by longitudes 60 to $170^{\circ} \mathrm{W}$, and north of $85^{\circ} \mathrm{S}$. In the Antarctic Peninsula region $\left(60-80^{\circ} \mathrm{W}\right)$ a northern bound of $74^{\circ} \mathrm{S}$ is also applied.

6. Victoria Land Coast-Ross Sea is north of $85^{\circ} \mathrm{S}$ and at an altitude $<2000 \mathrm{~m}$, with the exception of some localized peaks within the Transantarctic Mountains. It extends from 160 to $190^{\circ} \mathrm{E}$ (i.e. $170^{\circ} \mathrm{W}$ ) and incorporates most of the Ross Ice Shelf.

7. Dronning Maud Land Coast extends eastward from $30^{\circ} \mathrm{W}$ to $67^{\circ} \mathrm{E}$ (Lambert Glacier). The southernmost boundary lies at $75^{\circ} \mathrm{S}$ (where this region borders with the Weddell Sea Coast region), or at the $2000 \mathrm{~m}$ elevation contour elsewhere.

In addition to these seven climatic regions, we also produce reconstructions for a continent-wide Antarctic region. Broadscale East Antarctic (incorporating the climatic regions of the East Antarctic Plateau, as well as the Weddell Sea, Dronning Maud Land, Wilkes Land and Victoria Land coasts) and West Antarctic (incorporating the climatic regions of the West Antarctic Ice Sheet and Antarctic Peninsula) reconstructions are also presented. These additional reconstructions facilitate comparisons of our new results, using additional methods and an expanded database, with earlier findings of the Antarctica2k working group and subsequent research using the 2013 continent-scale reconstruction for Antarctic temperature.

\subsection{Data preprocessing}

All ice core records in the Antarctica2k database were assigned to one of the climatic regions described in Sect. 3.1 (as well as to East vs. West Antarctica and to the Antarcticwide classifications). The majority (94 out of 112) of ice core water isotope records in the database are based on oxygen isotope ratios $\left(\delta^{18} \mathrm{O}\right)$. In cases in which only deuterium isotope $(\delta \mathrm{D})$ data are available, the ice core time series were converted to an $\delta^{18} \mathrm{O}$ equivalent by dividing by 8 , a value 
that represents the slope of the global mean meteoric relationship of oxygen and deuterium isotopes in precipitation and is close to the ratio of 7.75 observed in surface Antarctic snow (Masson-Delmotte et al., 2008).

The ice core $\delta^{18} \mathrm{O}$ (and $\delta^{18} \mathrm{O}$ equivalent) records were compiled on a common annual average age scale. For records with sub-annual resolution this involved averaging all data from within a calendar year to generate an annual average data set. Pseudo-annual records were generated for the ice core $\delta^{18} \mathrm{O}$ records with lower-than-annual resolution. These pseudo annuals assume that each low-resolution isotopic value represents an average of the full-time interval that the sample covers. As such, a nearest-neighbour interpolation method was used to generate stepped (piecewise constant) pseudo-annual records that continue the measured isotopic value across all of the calendar years that it represents.

Records were next binned to 5- and 10-year-average resolution and converted to $\delta^{18} \mathrm{O}$ anomalies. This reduction in resolution is designed to reduce the influence of small age uncertainties between the records, as well as the non-climatic noise induced by post-deposition (e.g. wind erosion, diffusion) processes (Frezzotti et al., 2007; Ekaykin et al., 2014). The 5-year resolution records were converted to anomalies relative to their mean over the 1960-1990 CE interval, and records that do not include a minimum of six bins (30 years) of coverage since $1800 \mathrm{CE}$ are excluded based on length. Overall, 79 records in the new Antarctica2k water isotope database meet the minimum requirement of having at least 30 years of data coverage since $1800 \mathrm{CE}$. In some cases, records meet this minimum length requirement but do not include data for the full 1960-1990 CE reference interval. We adjust the mean value of each of these records by matching the mean $\delta^{18} \mathrm{O}$ of their most recent six bins (30 years) of data to the mean of all anomaly records from the same climatic region and over the same six-bin interval. We also produce normalized records by adjusting the variance in the records using the same reference period and method as for the anomaly records.

The 10-year resolution anomaly and normalized records were generated using the same method but using a reference period of 1900-1990 CE and a minimum data coverage of nine bins (90 years) since 0 CE. Similarly, records that do not include the full 1900-1990 CE reference period have the mean of their most recent nine-bin (90 years) interval adjusted to match the mean of all other anomaly records from the same region and over the same nine-bin interval. Overall, 67 records in the new Antarctica2k water isotope database meet the minimum requirement of having at least 90 years of data coverage since $0 \mathrm{CE}$.

Some regions of Antarctica, such as coastal and plateau sites in Dronning Maud Land, include dense networks of ice core data (Fig. S1). To reduce possible bias towards these data-rich regions, an additional data reduction method was used based on a $2^{\circ}$ latitude by $10^{\circ}$ longitude grid. Where multiple ice core records from the same climatic region fall within the same grid cell, their isotopic anomalies (or normalized data) are averaged to produce a single composite time series for the grid. This replicates the simple unweighted compositing method described in Sect. 3.3.1, but on the grid scale to reduce the representation of data-rich areas prior to the regional compositing. Figures S2 and S3 show the distribution of records by region that meet the six-bin (30 years) and nine-bin (90 years) minimum requirements for the 5- and 10-year composites, respectively, after the gridded data reduction step.

\subsection{Compositing methods}

We use a suite of reconstruction methods of varying complexity in order to assess robust trends and variability in Antarctic ice core $\delta^{18} \mathrm{O}$ records and temperature.

\subsubsection{Unweighted composites}

Our first reconstruction method involves calculating simple composites of $\delta^{18} \mathrm{O}$ anomalies. For each 5- or 10-year bin we calculate the mean $\delta^{18} \mathrm{O}$ anomaly across all records in the climatic region, as well as the distribution of $\delta^{18} \mathrm{O}$ anomalies within each bin (Figs. 2 and 3). This basic reconstruction method is analogous to that used for the Ocean $2 \mathrm{k}$ lowresolution reconstruction (McGregor et al., 2015). The benefit of this simple method is that it requires no weighting or calibration assumptions, which is advantageous for datasparse regions such as Antarctica (and the global oceans). The disadvantage is that it applies equal weighting to all records within a climatic region, which may introduce biases related to record length, location and climatic skill.

\subsubsection{Weighted composites based on site-level temperature regressions}

In order to avoid biases from uneven data sampling, we performed, for each region, a multiple regression between each site temperature and the relevant regional average temperature (Figs. 2 and 3). Most of the ice core records do not cover the full instrumental period; thus, it is problematic to use the $\delta^{18} \mathrm{O}$ anomalies directly to determine the regression vectors required for a weighted temperature reconstruction. Instead, we use the climate field reconstruction of NB2014 to estimate the weights: the annual mean temperature time series at the grid cell corresponding to each ice core site is extracted from the NB2014 product, and the regional average is also calculated for each reconstruction region. Regressionbased weightings are calculated based on the relationship between site temperature and regional average temperature, and the regression is performed for each combination of ice core records through time. The weights are then applied to the ice core $\delta^{18} \mathrm{O}$ anomalies to produce regional, averaged, standardized anomalies. 


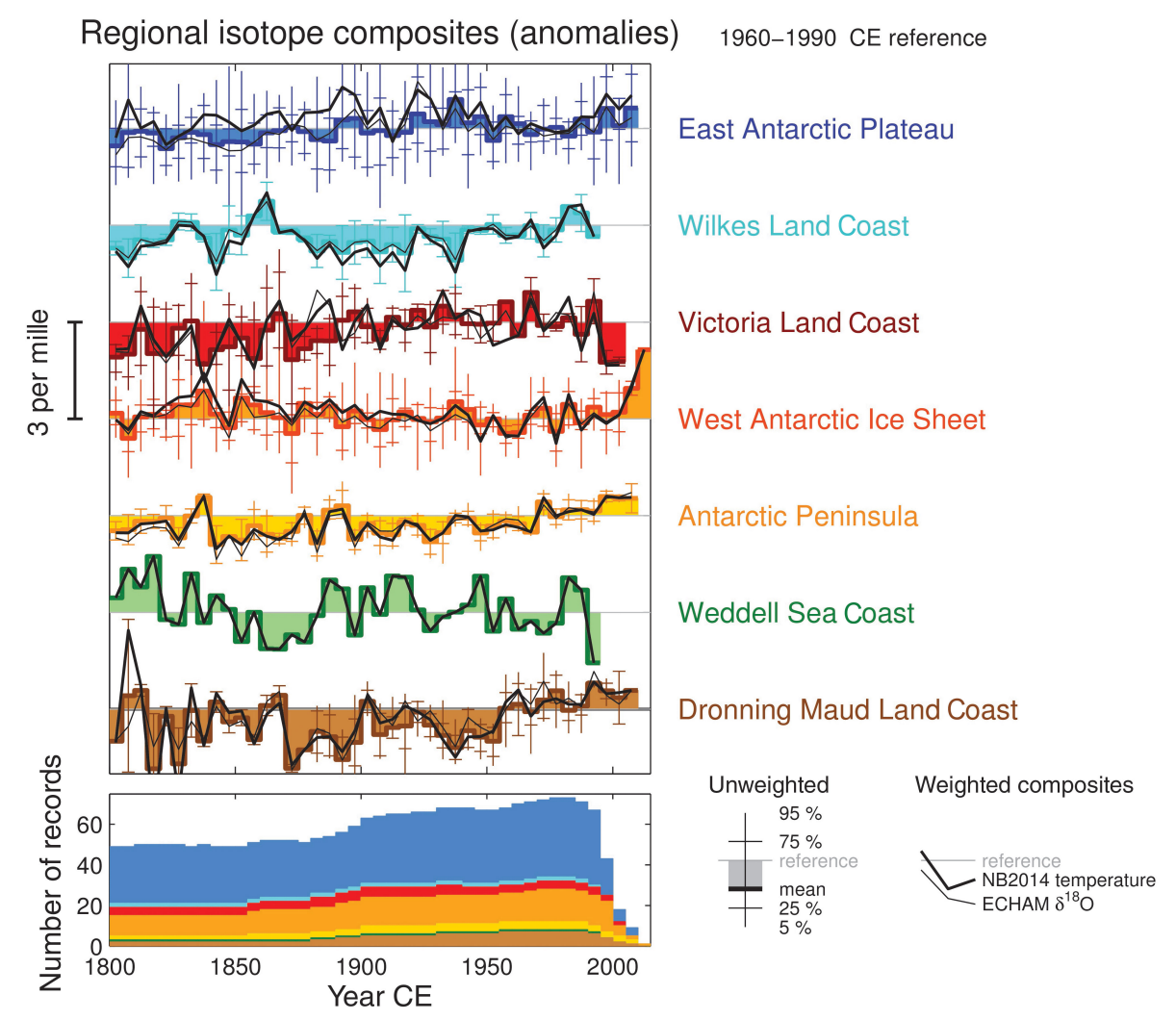

Figure 2. Regional $\delta^{18} \mathrm{O}$ composite reconstructions over the last 200 years using 5-year-binned anomaly data. Both unweighted composites and weighted composites (using both NB2014 temperature and ECHAM $\delta^{18} \mathrm{O}$ weighting methods) are shown. For each 5-year bin of the unweighted data, the mean $\delta^{18} \mathrm{O}$ anomaly across all records in the climatic region, as well as the distribution of $\delta^{18} \mathrm{O}$ anomalies within each bin, is calculated. All anomalies are expressed relative to the 1960-1990 CE interval. The number of records that contribute to the reconstructions for each region are displayed in the lower panel.

We further reproduced this regression method using both the $\delta^{18} \mathrm{O}$ and temperature field outputs from the ECHAM5wiso experiments. The regression of site $\delta^{18} \mathrm{O}$ compared to regional average $\delta^{18} \mathrm{O}$, or site temperature onto regional temperature, gave nearly identical weighting factors, supporting the use of the temperature field to calculate regressions. The effects of the different weighting methods on each regional isotopic composite, as well as the initial 10-year isotopic anomaly records, are reported in the Supplement (Figs. S4-S10). The small differences between ECHAM- and NB2014-based regressions were due to the lower resolution of ECHAM5-wiso, which does not include islands and topographic features such as Roosevelt Island and Law Dome. For this reason, we preferentially use the NB2014 data set for the temperature regression reconstruction method.

\subsection{Temperature reconstructions}

The relationship between $\delta^{18} \mathrm{O}$ and local surface temperature is complicated by the influence of a large range of processes (origin of moisture sources, intermittency in precipita- tion, snow drift, snow-air exchanges, snow metamorphism, diffusion in ice cores). It is not possible to consider each process independently because in many cases there are simply no observations to constrain them well enough. However, the atmospheric circulation often leads to several processes to be correlated (reduced sea ice, increased precipitation and warmer temperature, for instance). Here, we follow the classical approach, which is to perform a linear regression of ice core $\delta^{18} \mathrm{O}$ with local surface temperature on the regional average products. This method has the advantage of looking at all the climatic processes influencing $\delta^{18} \mathrm{O}$ in "bulk", and the use of regional average allows us to limit the influence of small-scale processes.

The lack of an overlap period between our site $\delta^{18} \mathrm{O}$ records and direct temperature observations makes the proxy calibration difficult. The CPS method (Sect. 3.4.4), which replicates the 2013 PAGES $2 \mathrm{k}$ reconstruction method, is limited to sites where this calibration is possible. To overcome this limitation and include the largest number of records, we also use models to scale the regional isotope composites. A first method uses ECHAM5-wiso to determine the regional $\delta^{18} \mathrm{O}$-temperature relationship in a mechanistic way 


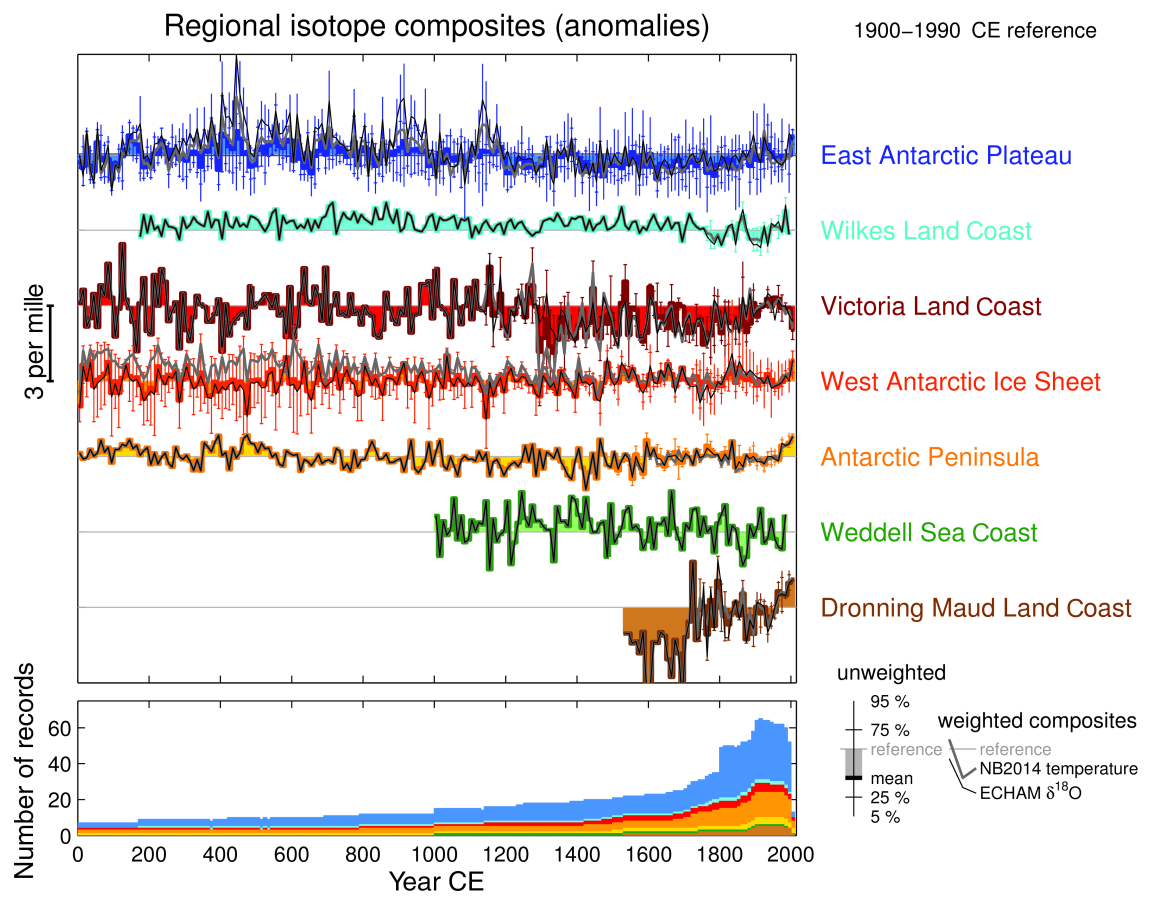

Figure 3. Regional $\delta^{18} \mathrm{O}$ composite reconstructions over the last 2000 years using 10-year-binned anomaly data. Both unweighted composites and weighted composites (using both NB2014 temperature and ECHAM $\delta^{18} \mathrm{O}$ weighting methods) are shown. For each 10 -year bin of the unweighted data, the mean $\delta^{18} \mathrm{O}$ anomaly across all records in the climatic region, as well as the distribution of $\delta^{18} \mathrm{O}$ anomalies within each bin, is calculated. All anomalies are expressed relative to the 1900-1990 CE interval. The number of records that contribute to the reconstructions for each region are displayed in the lower panel.

(Sect. 3.4.1). A second method uses a more statistical approach and simply scales the normalized record to the instrumental period temperature variance (Sect. 3.4.2). Both approaches are equally valid and share the same hypothesis: that the instrumental period (1979-2013) is representative of the longer-term climate variability. Finally, for the West Antarctic Ice Sheet region, an independent longer-term temperature record is available from borehole temperature measurements (Orsi et al., 2012). We use this independent temperature record to scale the long term 1000-1600 CE temperature trend for the West Antarctic Ice Sheet region to provide our best estimate of temperature change in line with current knowledge (Sect. 3.4.3).

In the figure captions, we refer to the different methods as "ECHAM", "NB2014" and "borehole", respectively.

\subsubsection{Scaling using model-based regional $\delta^{18} \mathrm{O}$-temperature relationships}

We use the coherent physical framework of the 1979$2013 \mathrm{CE}$ simulation performed at T106 resolution with ECHAM5-wiso to infer constraints on regional $\delta^{18} \mathrm{O}-$ temperature slopes through linear regression analysis between regional averages of simulated annual mean temperature and precipitation-weighted $\delta^{18} \mathrm{O}$ (Table 1). These regional $\delta^{18} \mathrm{O}$-temperature regressions were applied to the re- gional ice core composites $\left(\delta^{18} \mathrm{O}_{\text {region }}\right.$ anomalies) to scale them from $\delta^{18} \mathrm{O}$ to temperature units (Figs. 4 and 5) and produce temperature anomalies ( $\left.T_{\text {region }}\right)$. The correlation coefficient $\alpha_{\text {region }}$ is calculated using the York et al. (2004) method, taking into account uncertainties both in $T_{\text {region }}$ and in $\delta^{18} \mathrm{O}_{\text {region, }}$, with each prior uncertainty equal to $20 \%$ of the variance.

$T_{\text {region }}=\alpha_{\text {region }} \delta^{18} \mathrm{O}_{\text {region }}=\alpha_{\text {region }} \sum_{\text {sites } i} w_{i} \delta^{18} \mathrm{O}_{i}$

In this equation, $w_{i}$ represents the weights assigned to each site $i$, and $\delta^{18} \mathrm{O}_{i}$ the site $\delta^{18} \mathrm{O}$ anomalies in 5- or 10-yearaveraged records. The limited length of the observational period (1979-2013 CE) does not allow us to precisely estimate the slope $\alpha$ on 10-year averages, and we preferred to use 1 -year anomalies, for which the slopes are significant (Table 1), and apply these slopes to the 10-year-binned composites. This implies that the interannual $\delta^{18} \mathrm{O}$-temperature relationship comes from mechanisms that are also applicable to decadal-scale variability. It is impossible to further test this hypothesis without longer independent temperature records. The use of the ECHAM5-wiso isotope-enabled climate model is the most up-to-date tool we have to quantify the $\delta^{18} \mathrm{O}$-temperature on broad spatial-temporal scales and is our best tool to infer the $\delta^{18} \mathrm{O}$-temperature relationship in the absence of data. Its main limitation is the model resolu- 

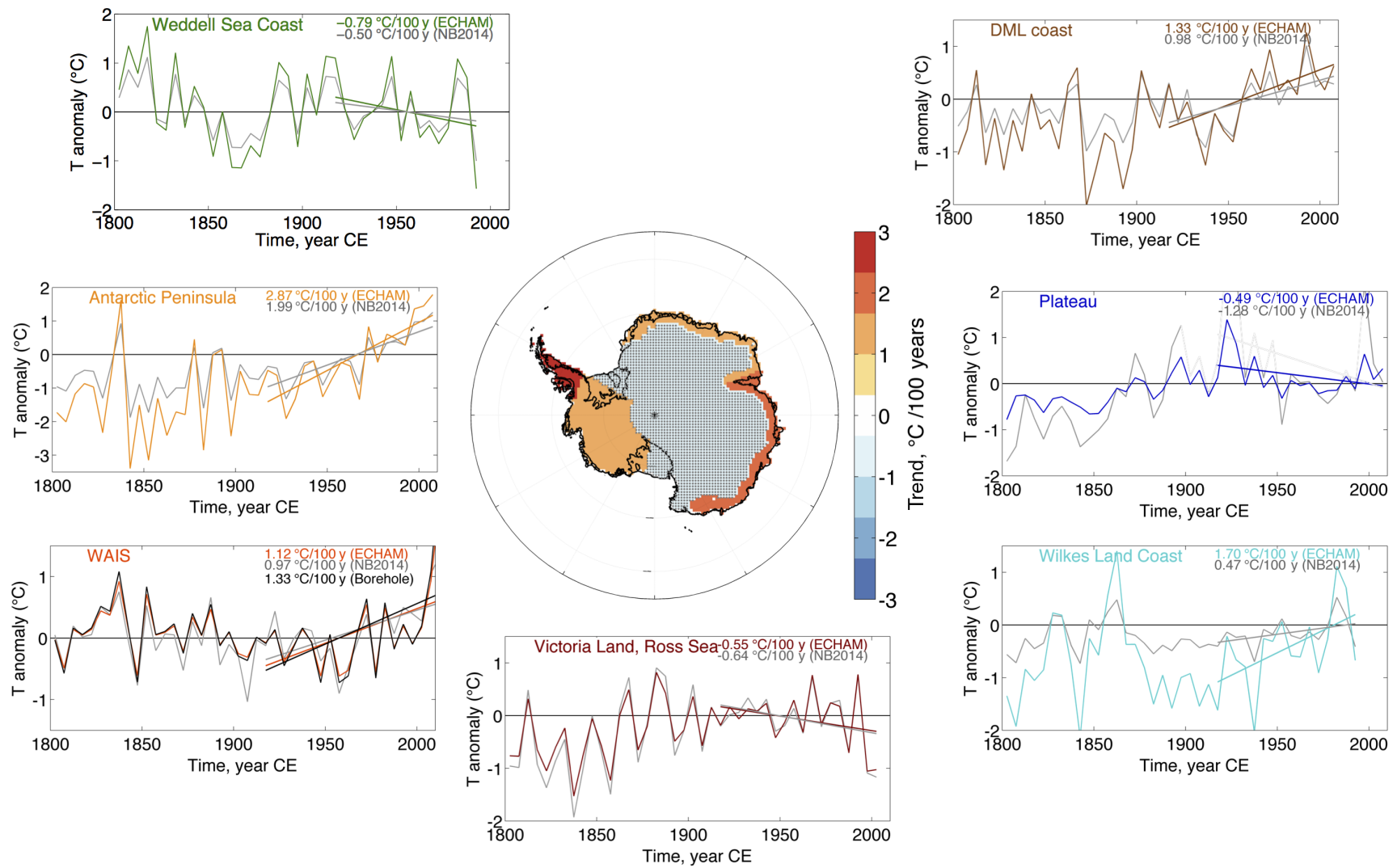

Figure 4. Regional temperature ( $T$ anomalies in ${ }^{\circ} \mathrm{C}$, referenced to the 1960-1990 CE interval) reconstructions using 5-year-binned data for the past 200 years. The weighing method is based on the correlation between site $T$ and regional $T$ from NB2014. The temperature scaling method is (i) based on the correlation between annual mean regional $\delta^{18} \mathrm{O}$ and regional $T$ from ECHAM5-wiso forced by ERAInterim (coloured lines) and (ii) scaled on the NB2014 target over 1960-1990 CE (grey lines), and the (iii) West Antarctic Ice Sheet region is adjusted to match the temperature trend between 1000 and $1600 \mathrm{CE}$ based on borehole temperature measurements (black line; Orsi et al., 2012). Linear trends are calculated over the last 100 years of the reconstructions (colours match associated reconstruction methods). The map at the centre reports regional trends over the last 100-year trend using 5-year data based on the ECHAM method adjusted for the West Antarctic Ice Sheet region to borehole data. Hatched areas are not significant $(p>0.05)$.

Table 1. Linear regression analysis (slope with $\pm 1 \sigma$ uncertainty, correlation coefficient $r$, and $p$ value) of the simulated $\delta^{18} \mathrm{O}-$ temperature relationships extracted from the ECHAM5-wiso model for each climatic region, as well as the broad East Antarctic, West Antarctic and whole of Antarctica regions.

\begin{tabular}{lrrrr}
\hline Geographic region & Slope $\left({ }^{\circ} \mathrm{C} \% o^{-1}\right)$ & Slope $\left(\%{ }^{\circ} \mathrm{C}^{-1}\right)$ & $r$ & $p$ value \\
\hline 1. East Antarctic Plateau & $0.95 \pm 0.05$ & $1.05 \pm 0.06$ & 0.62 & 0.0001 \\
2. Wilkes Land Coast & $1.91 \pm 0.11$ & $0.52 \pm 0.03$ & 0.44 & 0.0084 \\
3. Weddell Sea Coast & $1.01 \pm 0.06$ & $0.99 \pm 0.06$ & 0.34 & 0.0449 \\
4. Antarctic Peninsula & $2.50 \pm 0.15$ & $0.40 \pm 0.02$ & 0.31 & 0.0658 \\
5. West Antarctic Ice Sheet & $1.04 \pm 0.06$ & $0.96 \pm 0.05$ & 0.59 & 0.0002 \\
6. Victoria Land Coast & $0.83 \pm 0.05$ & $1.21 \pm 0.07$ & 0.49 & 0.0027 \\
7. Dronning Maud Land Coast & $1.08 \pm 0.06$ & $0.93 \pm 0.05$ & 0.39 & 0.0217 \\
\hline West Antarctica & $1.03 \pm 0.06$ & $0.97 \pm 0.05$ & 0.62 & 0.0001 \\
East Antarctica & $1.00 \pm 0.05$ & $1.00 \pm 0.05$ & 0.58 & 0.0002 \\
All Antarctica & $1.02 \pm 0.06$ & $0.98 \pm 0.05$ & 0.56 & 0.0004 \\
\hline
\end{tabular}

tion: it is missing some coastal topographical features, notably James Ross Island, Roosevelt Island, and Law Dome, and cannot faithfully represent regions where these sites are important. 


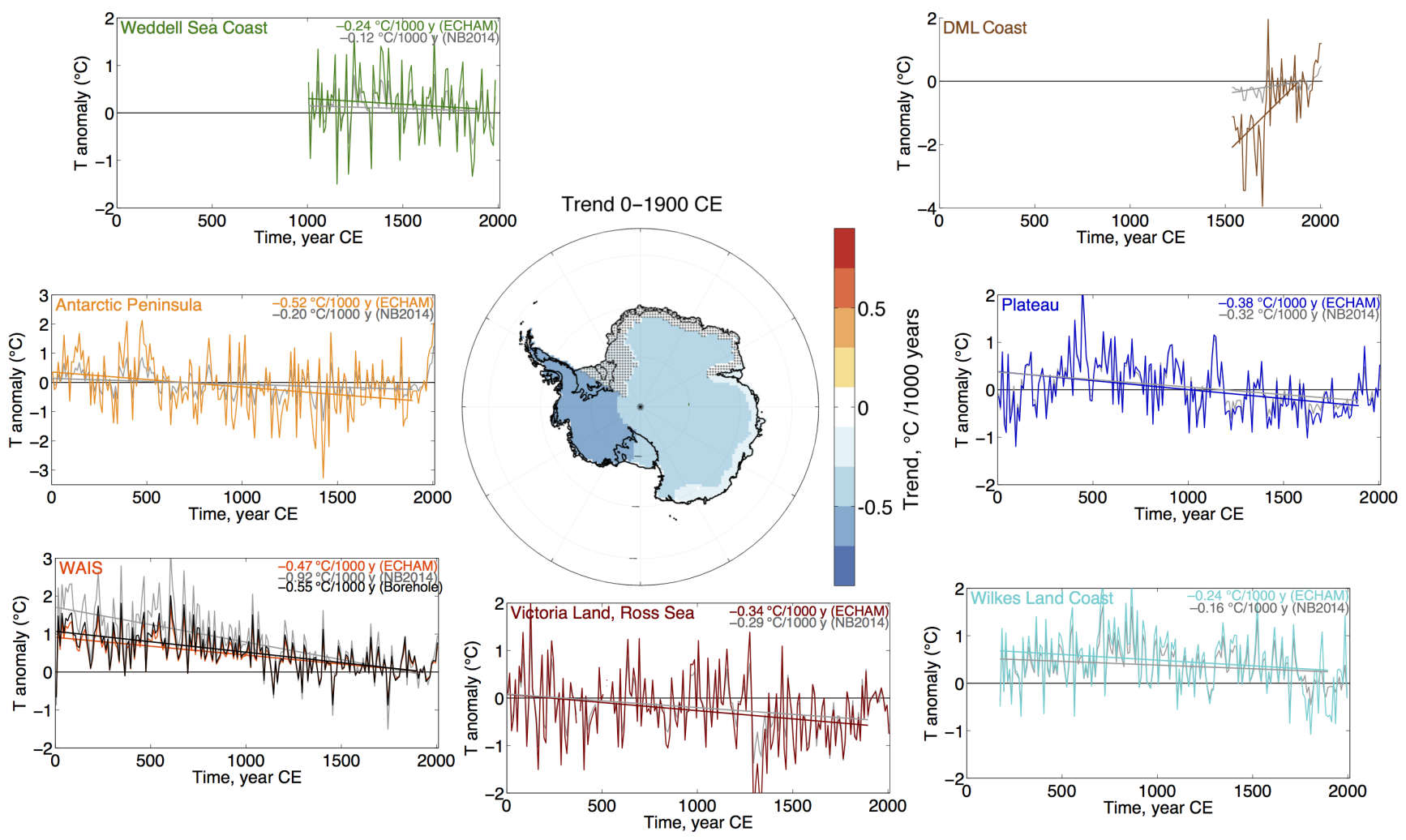

Figure 5. Regional temperature ( $T$ anomalies in ${ }^{\circ} \mathrm{C}$, referenced to the 1900-1990 CE period) reconstructions using 10-year data for the past 2000 years. Weighing method based on the correlation between site $T$ and regional $T$ from NB2014 forced by ERA-Interim. The temperature scaling method is (i) based on the correlation between annual mean regional $\delta^{18} \mathrm{O}$ and regional $T$ from ECHAM5-wiso forced by ERA-Interim (coloured lines) and (ii) scaled on the NB2014 target over 1960-2010 CE (grey lines), and the (iii) West Antarctic Ice Sheet region is adjusted to match the temperature trend between 1000 and $1600 \mathrm{CE}$ based on borehole temperature measurements (black line; Orsi et al., 2012). Linear trends are calculated over the period 0-1900 CE using 10-year-binned data. The map at the centre reports the trend values calculated between 0 and 1900 CE using 10-year data based on the ECHAM method adjusted to borehole data for the West Antarctic Ice Sheet region (the hatched area is not significant).

All regional $\delta^{18} \mathrm{O}$-temperature relationships produced by the ECHAM5-wiso output are statistically significant (at $95 \%$ confidence) with the exception of the Antarctic Peninsula. Weak correlations are also found for the Weddell Sea Coast $(r=0.34)$. Stronger correlation coefficients are obtained inland, for the larger-scale East and West Antarctic sectors, and maximum values $(r=0.62)$ are identified for the East Antarctic Plateau.

Similarly, the simulated regional $\delta^{18} \mathrm{O}$-temperature slopes are highest for Victoria Land $\left(1.21 \% 0^{\circ} \mathrm{C}^{-1}\right)$ and lowest for the Antarctic Peninsula $\left(0.40 \%{ }^{\circ} \mathrm{C}^{-1}\right)$. This low slope for the Antarctic Peninsula does not agree with the temporal $\delta^{18} \mathrm{O}$-temperature relationship that has been reported for the highly resolved James Ross Island ice core $\left(0.86 \%{ }^{\circ} \mathrm{C}^{-1}\right.$; Abram et al., 2011), while it is similar to one reported for the Gomez ice core $\left(0.5 \%{ }^{\circ} \mathrm{C}^{-1}\right.$; Thomas et al., 2009) and precipitation samples collected at the O'Higgins Station $\left(0.41 \% 0^{\circ} \mathrm{C}^{-1}\right.$; Fernandoy et al., 2012). ECHAM finds that the only site on the peninsula with a significant correlation between $\delta^{18} \mathrm{O}$ and temperature is Bruce Plateau $\left(66^{\circ} \mathrm{S}\right.$, $\left.64^{\circ} \mathrm{W}\right)$ (slope $=0.63 \pm 0.58 \% 0^{\circ} \mathrm{C}^{-1}, r=0.13, p=0.03$ ), and the overall low $\delta^{18} \mathrm{O}$-temperature slope is largely attributable to model resolution. We expect that the ECHAM scaling will produce a temperature reconstruction with a high-amplitude bias in the Antarctic Peninsula.

High slopes similar to the Victoria Land are identified in the inland East Antarctic Plateau, Weddell Sea Coast and West Antarctic Ice Sheet regions (1.05, 0.99 and $0.96 \% 0^{\circ} \mathrm{C}^{-1}$, respectively), together with intermediate values in coastal Dronning Maud Land with a $0.93 \% 0^{\circ} \mathrm{C}^{-1}$ mean slope. On the scale of the whole Antarctic ice sheet, the overall temporal slope is dominated by inland regions and simulated at $0.98 \% 0^{\circ} \mathrm{C}^{-1}$. This analysis is more thoroughly examined in a study comparing an isotopic data set from surface snow, snowfalls and ice cores (Sentia Goursaud, personal communication, 2017). 


\subsubsection{Scaling based on NB2014 variance}

In addition, we used an independent method of scaling the normalized $\delta^{18} \mathrm{O}$ anomalies to the $\mathrm{SD}(\sigma(T))$ of the regional temperature from NB2014, over the 1960-1990 CE interval for the 5-year-binned averages, and the period 1960$2010 \mathrm{CE}$ for the 10-year-binned averages. This scaling is similar to the one used for the CPS method (see next section).

$T_{\text {region }}=\sigma(T)_{\text {region }} \delta^{18} \mathrm{O}_{\text {region }}($ normalized $)$

This scaling method implies that the $\delta^{18} \mathrm{O}$-temperature relationship can be inferred from the ratio of temperature to $\delta^{18} \mathrm{O} \mathrm{SD}$, which would be true if the relationship between the two were purely linear. If some of the $\delta^{18} \mathrm{O}$ variance is due to something other than temperature, this scaling will underestimate temperature variations. This method also assumes that the last 30 to 50 years provide a good estimate of the 5- or 10-year temperature variance. In the absence of longer temperature reconstructions, this is the best estimate of $\sigma(T)_{\text {region }}$ that we can provide.

\subsubsection{Scaling based on borehole temperature for the WAIS region.}

In the West Antarctic Ice Sheet region, the approaches described above give different results (Figs. 4 and 5), with the first method (temperature scaling from the $\delta^{18} \mathrm{O}-T$ relationship in ECHAM5-wiso) giving a smaller amplitude. At WAIS Divide, there is an independent temperature record, which can be used to scale the long-term temperature evolution. We used the borehole temperature reconstruction at WAIS Divide (Orsi et al., 2012) to adjust the amplitude of temperature variations, matching the cooling trend over the period $1000-1600 \mathrm{CE}\left(-1.1^{\circ} \mathrm{C} 1000 \mathrm{yr}^{-1}\right)$, with a correction factor relating the WAIS Divide site to the West Antarctic region $\left(c=\sigma_{\text {WAIS }} / \sigma_{\text {WDC }}=0.65\right)$, with $\sigma_{\text {WAIS }}$ the SD of the annual NB2014 WAIS regional mean data set, and $\sigma_{\text {WDC }}$ the SD of the annual NB2014 time series at the WAIS Divide site, which gives a $1000-1600 \mathrm{CE}$ cooling trend of $-0.76^{\circ} \mathrm{C}$.

This scaling is actually in line with the other two scalings: 1000-1600 CE slope of $-0.65^{\circ} \mathrm{C}$ for ECHAM and $-1.01^{\circ} \mathrm{C}$ for NB2014 scaling. The temperature calibration presented here is the best estimate we can provide with current knowledge, but we expect it to be revised in the future, with more precise $\delta^{18} \mathrm{O}$ modelling and more independent quantitative temperature reconstructions.

\subsubsection{Replication of the 2013 Antarctica2k reconstruction method}

To facilitate comparison with the preceding Antarctica2k temperature reconstruction published by the PAGES $2 \mathrm{k}$ Consortium (2013), we apply their reconstruction method to the updated ice core isotope data collection. The method is a simple CPS approach (Jones et al., 2009), updated from Schneider et al. (2006) and implemented similarly to Neukom et al. (2014). We apply this method to all subregions defined above, the broad East and West Antarctic divisions and to the Antarctic-wide database, replicating the Antarctic reconstructions presented in the PAGES 2k Consortium (2013) study.

First, the annual-average records are allocated to the climatic regions as defined above. The following steps are then repeated for each region separately. Second, only the records with no missing values in the 1961-1991 CE calibration period are selected. These records are then scaled to mean zero and unit SD over their common interval of data availability. Next, the normalized records are correlated with the NB2014 regional mean temperatures over 1961-1991 CE. Between 0 and $33 \%$ of the ice core records within each region have negative correlations (physically implausible) with the target and are removed from the proxy matrix. A composite of the remaining records is then calculated by creating a weighted average, where the weighting of each ice core record is based on its temperature correlation from the previous step. The composite is then scaled to the mean and SD of the NB2014 regional temperatures over the 1961-1991 CE period. The compositing and scaling steps are carried out with a nested approach, i.e. repeated for all periods with different proxy data availability.

In the reconstruction of the PAGES 2k Consortium (2013), three records were infilled with neighbouring sites to have no missing data in the calibration window: WDC06A was infilled with data from WDC05A, and Siple Station and Plateau Remote records were infilled by a least median of squares multiple linear regression using nearby records (PAGES 2k Consortium, 2013). To allow comparison, we also used the infilled data for these records. Thus, the only difference from the reconstruction of PAGES 2k Consortium (2013) is that we use an extended proxy database with more records and an updated temperature target (NB2014 instead of Steig et al., 2009).

While this CPS approach allows a quantitative calibration to the NB2014 temperature data, it has some limitations compared to the methods above. First, in this implementation it allows only the inclusion of data covering the calibration period, thereby removing more than half of the available records (62 out of 112). Second, the calibration period is extremely short and therefore individual years (for example with outliers) can significantly bias the reconstruction, and reasonable validation of the reconstruction is hardly possible. The main difference from the other compositing methods described above is the weight of each record and the interval over which the data are standardized. 


\section{Results and discussion}

We use the varying reconstruction methods to identify robust trends in the Antarctic ice core database. We present results based on isotopic trends, as well as temperature reconstructions, and examine these for the seven climatic regions and for the larger-scale Antarctic regions (Sect. 4.1), compare our results to the previous Antarctic temperature reconstruction (Sect. 4.2), and investigate the link between temperature and volcanic activity (Sect. 4.3).

\subsection{Regional-scale $\delta^{18} \mathrm{O}$ and temperature reconstructions}

For each of the seven climatic regions in Fig. S2 (unweighted isotope anomalies) and Fig. 2 (weighted and unweighted data), 5-year-binned $\delta^{18} \mathrm{O}$ composite records since $1800 \mathrm{CE}$ are reported. The unweighted composites are shown with respect to the distributions of data within each bin and expressed relative to the 1960-1990 CE interval. Figure 2 also shows the reconstructions that are obtained by weighting the records within each region based on the NB2014 temperature field and by the ECHAM5-wiso $\delta^{18} \mathrm{O}$ field. Figure 3 (and Fig. S3) shows equivalent data, but for 10-year averages since 0 CE relative to the 1900-1990 CE interval.

The highest density of ice core records is present in the last century, but these are not evenly distributed over Antarctica (Fig. S1), with most of the records in the plateau and coastal areas of Dronning Maud Land and across the West Antarctic Ice Sheet. Conversely, only one and three records are present in the Weddell Sea and Wilkes Land coastal areas, respectively.

In order to separate the uncertainties due to the stacking procedure from uncertainties in the temperature scaling, we first discuss the main features of the unweighted regional $\delta^{18} \mathrm{O}$ anomalies (Sect. 4.1.1) and then proceed to discuss the weighted regional $\delta^{18} \mathrm{O}$ anomalies, and finally the temperature reconstructions. The weighted and unweighted composites produce similar results for the seven climatic regions (see Figs. S4-S10 in the Supplement), suggesting that our reconstructions are robust, and the composites do not depend on the exact methodology used (Figs. 2 and 3). There are two exceptions to this: the Antarctic Plateau (Fig. S4), where the many sites in Dronning Maud Land perhaps still bias the simple average towards this area even with the gridded data-reduction process, and the West Antarctic Ice Sheet (Fig. S8), where the two long records from WAIS Divide and Roosevelt Island (RICE) have diverging trends for much of the last 2000 years. The weighted reconstruction gives a higher weight to WAIS Divide, which maintains a longterm negative isotopic trend over the last $2 \mathrm{kyr}$ in this region (see Sect. 4.1.2). We further checked that WAIS Divide is indeed more representative of temperatures averaged across the West Antarctic Ice Sheet region than RICE, looking at temperature correlation maps that use the NB2014 tempera- ture field (Fig. S8). The temperature reconstructions obtained with the different methods are further shown in Fig. S15.

We assess trends for the seven climatic regions (and in the larger-scale Antarctic groupings) for the reconstructions prior to $1900 \mathrm{CE}$ (up to 1900 years length) (Sect. 4.1.2), and since 1900 CE (up to 110 years length) (Sect. 4.1.3), and we estimate the significance of the most recent 100-year trend relative to natural variability (Sect. 4.1.4).

\subsubsection{Trend significance in unweighted composites}

We first use a Monte Carlo approach to assess the significance of trends in the unweighted composites. This test is designed to test the significance of trends in relation to the distribution of data within each bin of the isotopic composites. For each bin in which two or more ice cores contribute data, we scale random Gaussian data about the median value and $\pm 2 \sigma$ distribution of isotopic data within that bin. We then sample from this scaled Gaussian data to produce 10000 simulations of each regional composite. We then assess the proportion of ensemble members that produce trends of the same sign as the mean composite and the proportion of ensemble members for which the trend is of the same sign as the mean composite and also significant at greater than $95 \%$ confidence. These trend analyses are based on 10-yearbinned isotopic anomalies for trends prior to $1900 \mathrm{CE}$ and 5-year-binned data for trends over the last 100 years of the composites (although equivalent results are found if 10-yearbinned data are used to assess trends in the last 100 years).

Results of unweighted composite trend analysis are summarized in Table 2. This analysis shows that for the unweighted composites the long-term cooling trend from 0 to 1900 CE is only significant for the East Antarctic Plateau. Visual examination of the unweighted composites (Fig. 3) suggests that many of the other climate regions appear to also have a negative unweighted isotopic trend over part of the last 2000 years (e.g. Wilkes Land and West Antarctic Ice Sheet regions), but these trends are not significant in the unweighted composites when calculated across the full interval from 0 to $1900 \mathrm{CE}$. The Victoria Land Coast trend prior to $1900 \mathrm{CE}$ is not significant in the mean or median unweighted composites, but over the interval in which two or more ice cores contribute to the composites the Monte Carlo assessments indicate that negative isotopic trends are produced in all 10000 ensemble members and are significant $(p<0.05)$ more often than can be explained by chance alone.

The significant trend that is produced in the unweighted composite for the East Antarctic Plateau climate region is also evident in the broader East Antarctic compilation and for the Antarctic continent-scale composite. The continentscale cooling trend produced in unweighted composites using the expanded Antarctica2k database is in agreement with the PAGES 2k Consortium (2013) results for which a longterm cooling trend over the Antarctic continent was identified. It is also consistent with robust pre-industrial cooling 
Table 2. Summary of trend statistics for isotopic anomalies using unweighted composites. Trends are expressed as isotopic anomalies, in per mille $\delta^{18} \mathrm{O}$ per decade units. Trends and their significance ( $p$; based on the Student's $t$ statistic) are calculated using a linear additive model and reported for the mean and median composites. Monte Carlo testing is applied to 10000 ensemble members based on the unweighted composite distributions, which are assessed to determine the percentage of trends with the same sign as the mean trend and the percentage with the same sign and a significance of $p<0.05$. Bold values indicate mean and median trends with a significance of $p<0.05$ and Monte Carlo simulations where significant; same-signed trends exceed $5 \%$ of the ensemble.

\begin{tabular}{|c|c|c|c|c|c|c|}
\hline Region & \multicolumn{3}{|c|}{ Pre-1900 CE trends } & \multicolumn{3}{|c|}{ Last-100-year trends } \\
\hline 2. Wilkes Land Coast & $0.017(0.444)$ & $0.017(0.444)$ & $80.6(2.3)$ & $0.098(0.001)$ & $0.098(0.001)$ & $100(90.5)$ \\
\hline 3. Weddell Sea Coast & $-0.002(0.376)$ & $-0.002(0.376)$ & - & $-0.060(0.318)$ & $-0.060(0.318)$ & - \\
\hline 4. Antarctic Peninsula & $0.006(0.188)$ & $0.004(0.361)$ & $84.3(2.9)$ & $0.112(0.000)$ & $0.111(0.000)$ & $100(98.2)$ \\
\hline 7. Dronning Maud Land Coast & $-0.032(0.366)$ & $-0.027(0.448)$ & $95.3(0.1)$ & $0.147(0.000)$ & $0.158(0.001)$ & $100(99.8)$ \\
\hline West Antarctica & $0.000(0.437)$ & $-0.001(0.118)$ & $95.57(11.2)$ & $0.054(0.021)$ & $0.082(0.001)$ & $100(79.8)$ \\
\hline East Antarctica & $-0.003(0.000)$ & $-0.002(0.000)$ & $100(100)$ & $0.037(0.035)$ & $0.064(0.003)$ & $99.8(55.1)$ \\
\hline All Antarctica & $-0.002(0.000)$ & $-0.002(0.000)$ & $100(99.5)$ & $0.044(0.005)$ & $0.073(0.000)$ & $99.9(76.2)$ \\
\hline
\end{tabular}

trends that have been identified in other continental reconstructions (PAGES 2k Consortium, 2013) and in the global oceans (McGregor et al., 2015).

Isotopic trends in the last 100 years of the unweighted composites show significant positive trends across a number of regions. In particular, significant isotopic trends, indicative of climate warming, are evident in the unweighted composites for the Antarctic Peninsula and the Wilkes Land and Dronning Maud Land coasts. The West Antarctic Ice Sheet region does not display a significant $(p<0.05)$ positive trend in the mean or median of the unweighted composites, but the Monte Carlo analysis across the distribution of isotopic data within each 10-year bin suggests that positive trends are produced in $99.5 \%$ of the 10000 simulations and are significant $(p<0.05)$ more often than can be explained by chance alone (20.5\% of simulations). Similarly, the Victoria Land-Ross Sea region shows a negative but insignificant trend in the mean and median composites, but in the Monte Carlo simulations this negative (cooling) trend is produced in $99.9 \%$ of ensemble members and is significant in $13.6 \%$ of ensemble members. The apparent inverse isotopic trends during the last century between the Victoria Land-Ross Sea region and the West Antarctic Ice Sheet and Antarctic Peninsula regions may be indicative of dynamical processes in the Amundsen Sea sector, which on interannual timescales are known to cause opposing climate anomalies between these regions.

The PAGES 2k Consortium (2013) study concluded that Antarctica was the only continent-scale region to not see the long-term cooling trend of the past 2000 years reverse to recent significant warming. However, on the regional scale examined in this study recent significant warming is suggested by many of the unweighted isotopic composites, particularly for coastal regions of Antarctica and the West Antarctic Ice Sheet. It should be stressed that these results are based only upon the simple unweighted compositing of the regional isotopic data, and the significance of trends is further assessed in the following section after weighting of the individual ice core records based on how representative they are of isotopic and temperature variability within each climatic region.

\subsubsection{Long-term trends in weighted reconstructions}

To extend this trend analysis further, we next assess the pre1900 CE (Fig. 5) trends in the temperature reconstructions produced by scaling the ice core data based on our different approaches (see Sect. 3.3.3). We estimate the uncertainty of the slope based on the $\pm 2 \sigma$ uncertainty in the regression parameters. The robustness of the slope estimation to individual data points was further checked by taking out $10 \%$ of data points randomly and calculating the slope again, but the uncertainty estimate this yields is much smaller than the uncertainty based on regression parameters. The slopes obtained by each of the temperature scaling methods are presented in Table 3. The uncertainty in the amplitude of the 0-1900 CE trend is dominated by the uncertainty in the temperature scaling of the composite. To make the discussion clear, we first focus on the trend in terms of normalized $\delta^{18} \mathrm{O}$ anomalies, with respect to the 1900-1990 CE periods, which circumvent the temperature scaling issues.

The period 0-1900 CE exhibits significant negative trends in most regions, from -0.4 to $-1.3 \sigma 1000 \mathrm{yr}^{-1}$. The trend is largest in the West Antarctic Ice Sheet $(-1.3 \pm$ $\left.0.2 \sigma 1000 \mathrm{yr}^{-1}\right)$, Victoria Land $\left(-0.9 \pm 0.4 \sigma 1000 \mathrm{yr}^{-1}\right)$ and the Antarctic Plateau $\left(-0.8 \pm 0.3 \sigma 1000 \mathrm{yr}^{-1}\right)$ regions. It is smaller but still significant for the Wilkes Land Coast 

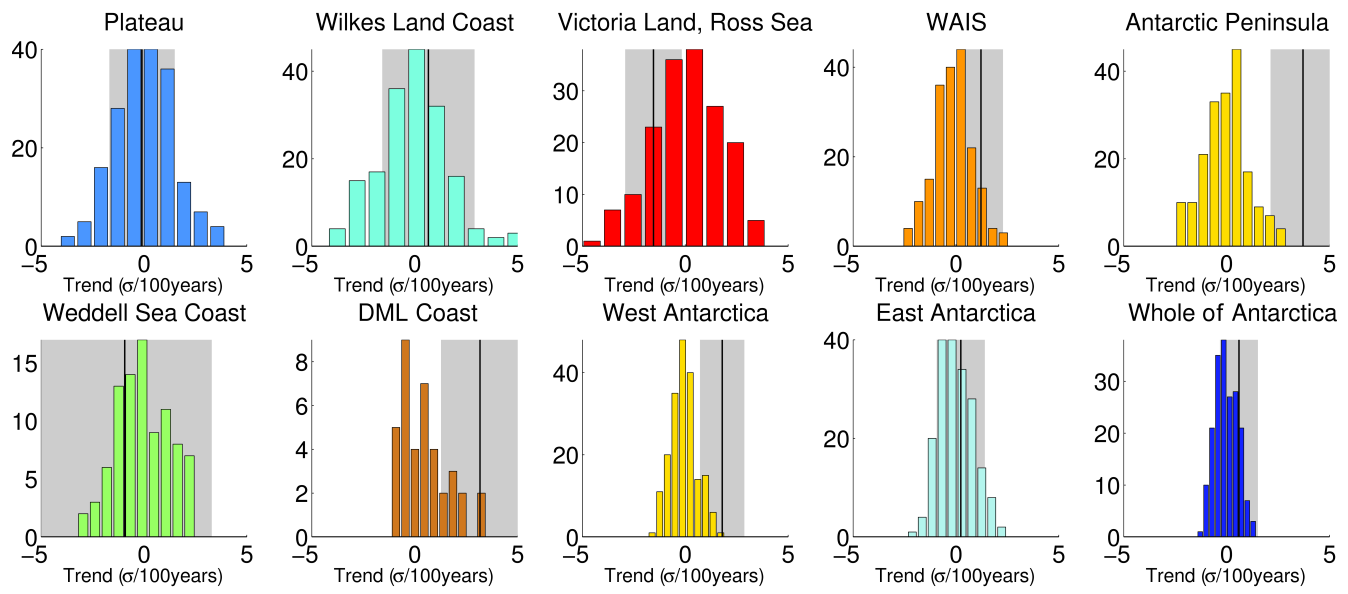

Figure 6. Histograms showing the distributions of all 100-year trends on normalized, weighted composites over the last 2000 years. Distributions are shown for each climatic region, as well as for East, West and whole of Antarctica composites, and are calculated on 10-year-binned composites. The solid vertical lines represent the most recent 100-year trend in each reconstruction, and grey shading corresponds to the $5-95 \%$ uncertainty range of the last 100-year trends. Only for the Antarctic Peninsula does the most recent 100-year trend stand out as unusual compared to the natural range of century-scale trends over the last 2000 years.

Table 3. Trend analysis of the period 0-1900 CE (or shorter depending on maximum record length) for the various temperature scaling approaches detailed in Sect. 3.4 .

\begin{tabular}{|c|c|c|c|c|c|c|c|c|}
\hline & & & \multicolumn{2}{|c|}{ ECHAM } & \multicolumn{2}{|c|}{ NB2014 } & \multicolumn{2}{|c|}{ Borehole } \\
\hline Geographic region & $\begin{array}{r}\text { Start } \\
\text { date }\end{array}$ & $\begin{array}{l}\text { End } \\
\text { date }\end{array}$ & $\begin{array}{r}\text { Slope } \\
\left({ }^{\circ} \mathrm{C} 1000 \mathrm{yr}^{-1}\right)\end{array}$ & $p$ value & $\begin{array}{r}\text { Slope } \\
\left({ }^{\circ} \mathrm{C} 1000 \mathrm{yr}^{-1}\right)\end{array}$ & $p$ value & $\begin{array}{r}\text { Slope } \\
\left({ }^{\circ} \mathrm{C} 1000 \mathrm{yr}^{-1}\right)\end{array}$ & $p$ value \\
\hline 1. East Antarctic Plateau & 0 & 1900 & $-0.38 \pm 0.14$ & $<0.0001$ & $-0.32 \pm 0.12$ & $<0.0001$ & $\mathrm{NaN}$ & $\mathrm{NaN}$ \\
\hline 2. Wilkes Land Coast & 170 & 1900 & $-0.24 \pm 0.17$ & 0.0072 & $-0.16 \pm 0.13$ & 0.0161 & $\mathrm{NaN}$ & $\mathrm{NaN}$ \\
\hline 3. Weddell Sea Coast & 1000 & 1900 & $-0.24 \pm 0.54$ & 0.3763 & $-0.12 \pm 0.27$ & 0.3763 & $\mathrm{NaN}$ & $\mathrm{NaN}$ \\
\hline 4. Antarctic Peninsula & 0 & 1900 & $-0.52 \pm 0.23$ & $<0.0001$ & $-0.20 \pm 0.09$ & $<0.0001$ & $\mathrm{NaN}$ & $\mathrm{NaN}$ \\
\hline 5. West Antarctic Ice Sheet & 0 & 1900 & $-0.47 \pm 0.10$ & $<0.0001$ & $-0.92 \pm 0.16$ & $<0.0001$ & $-0.55 \pm 0.11$ & $<0.0001$ \\
\hline 6. Victoria Land Coast & 0 & 1900 & $-0.34 \pm 0.18$ & 0.0003 & $-0.29 \pm 0.12$ & $<0.0001$ & $\mathrm{NaN}$ & $\mathrm{NaN}$ \\
\hline 7. Dronning Maud Land Coast & 1530 & 1900 & $5.96 \pm 3.27$ & 0.0007 & $0.97 \pm 0.62$ & $\mathbf{0 . 0 0 3 2}$ & $\mathrm{NaN}$ & $\mathrm{NaN}$ \\
\hline West Antarctica & 0 & 1900 & $-0.24 \pm 0.07$ & $<0.0001$ & $-0.44 \pm 0.10$ & $<0.0001$ & $-0.55 \pm 0.10$ & $<0.0001$ \\
\hline East Antarctica & 0 & 1900 & $-0.30 \pm 0.10$ & $<0.0001$ & $-0.32 \pm 0.10$ & $<0.0001$ & NaN & $\mathrm{NaN}$ \\
\hline \multirow[t]{2}{*}{ All Antarctica } & 0 & 1900 & $-0.36 \pm 0.08$ & $<0.0001$ & $-0.40 \pm 0.08$ & $<0.0001$ & $-0.26 \pm 0.06$ & $<0.0001$ \\
\hline & \multicolumn{4}{|c|}{ Normalized } & \multicolumn{4}{|c|}{ CPS } \\
\hline Geographic region & & $\begin{array}{r}\text { Slope } \\
\left(\sigma 1000 \mathrm{yr}^{-1}\right)\end{array}$ & $p$ value & & $\begin{array}{r}\text { Slope } \\
\left({ }^{\circ} \mathrm{C} 1000 \mathrm{yr}^{-1}\right)\end{array}$ & $p$ value & $\begin{array}{r}\text { Start } \\
\text { date }\end{array}$ & $\begin{array}{l}\text { End } \\
\text { date }\end{array}$ \\
\hline 1. East Antarctic Plateau & & $-0.76 \pm 0.28$ & $\mathbf{0}$ & & $-0.15 \pm 0.06$ & $\mathbf{0}$ & 10 & 1900 \\
\hline 2. Wilkes Land Coast & & $-0.59 \pm 0.48$ & 0.0161 & & $-0.10 \pm 0.07$ & 0.008 & 180 & 1900 \\
\hline 3. Weddell Sea Coast & & $-0.41 \pm 0.92$ & 0.3763 & & $-0.09 \pm 0.27$ & 0.4935 & 1000 & 1900 \\
\hline 4. Antarctic Peninsula & & $-0.50 \pm 0.23$ & $\mathbf{0}$ & & $-0.09 \pm 0.09$ & 0.0479 & 0 & 1900 \\
\hline 5. West Antarctic Ice Sheet & & $-1.32 \pm 0.23$ & $\mathbf{0}$ & & $-0.59 \pm 0.08$ & $\mathbf{0}$ & 0 & 1900 \\
\hline 6. Victoria Land Coast & & $-0.89 \pm 0.39$ & $\mathbf{0}$ & & $-0.54 \pm 0.58$ & 0.0661 & 1140 & 1900 \\
\hline 7. Dronning Maud Land Coast & & $4.98 \pm 3.20$ & 0.0032 & & $\mathrm{NaN}$ & $\mathrm{NaN}$ & 1890 & 1900 \\
\hline West Antarctica & & $-0.76 \pm 0.16$ & $\mathbf{0}$ & & $-0.55 \pm 0.07$ & $\mathbf{0}$ & 0 & 1900 \\
\hline East Antarctica & & $-0.59 \pm 0.19$ & $\mathbf{0}$ & & $-0.18 \pm 0.06$ & $\mathbf{0}$ & 10 & 1900 \\
\hline All Antarctica & & $-0.76 \pm 0.15$ & $\mathbf{0}$ & & $-0.38 \pm 0.05$ & $\mathbf{0}$ & 0 & 1900 \\
\hline
\end{tabular}

$\left(-0.6 \pm 0.5 \sigma 1000 \mathrm{yr}^{-1}, p=0.007\right)$ and Antarctic Peninsula $\left(-0.5 \pm 0.2 \sigma 1000 \mathrm{yr}^{-1}\right)$. It is insignificant on the Weddell Sea Coast $(p=0.4)$, and the data set is not long enough to estimate millennial-scale trends on the Dronning Maud Land Coast. These observations indicate a broad-scale cool- ing trend over the continent, which is comparable in amplitude to the variance over the past 100 years. As previously mentioned, the 0-1900 CE negative trend is largest in the normalized data sets for the West Antarctic Ice Sheet region, but this feature masks subregional-scale differences, with 
the RICE record indicating increasing rather than decreasing anomalies. This result is puzzling because both WAIS Divide (to the west) and Victoria Land cores (e.g. Victoria Lower Glacier, to the east of RICE) show a clear cooling trend prior to $1900 \mathrm{CE}$, and together this points to a more complex picture of the evolution of the atmospheric circulation around the Ross Sea than can be captured with the current network of cores. The RICE $\delta^{18} \mathrm{O}$ record, situated on Roosevelt Island on the Ross Ice Shelf, is more influenced by air masses from the eastern Ross Sea sector than the rest of the West Antarctic Ice Sheet region, which is influenced predominantly by air masses from the Amundsen Sea (Neff et al., 2015; Emanuelsson et al., 2017). Moreover, borehole temperature and $\delta^{15} \mathrm{~N}$ thermal fractionation records at RICE highlight some notable differences in the isotope temperature reconstruction, which suggest that sea ice extent exerts an important control, perhaps masking aspects of the longer-term temperature trends in the region (Bertler et al., 2017).

Over the period from 0 to $1900 \mathrm{CE}$ the ECHAM temperature scaling suggests that the mean cooling trends are $-0.38^{\circ} \mathrm{C} 1000 \mathrm{yr}^{-1}$ for the East Antarctic Plateau, $-0.47^{\circ} \mathrm{C}$ $1000 \mathrm{yr}^{-1}$ for the West Antarctic Ice Sheet, $-0.52^{\circ} \mathrm{C}$ $1000 \mathrm{yr}^{-1}$ for the Antarctic Peninsula and $-0.34{ }^{\circ} \mathrm{C}$ $1000 \mathrm{yr}^{-1}$ for Victoria Land. Coastal East Antarctic regions do not show significant trends (Weddell Sea, Dronning Maud Land Coast and Wilkes Land Coast). The NB2014 temperature scaling produces lower trends overall (Table 3), except for the West Antarctic Ice Sheet where the trend doubles $\left(-0.92{ }^{\circ} \mathrm{C} 1000 \mathrm{yr}^{-1}\right)$. The trend in the West Antarctic Ice Sheet region can be assessed independently by comparing the WAIS composite to the borehole temperature record of Orsi et al. (2012) at WAIS Divide for the period 1000-1600 CE. The borehole-derived trend at WAIS Divide is $-0.55^{\circ} \mathrm{C} 1000 \mathrm{yr}^{-1}$ for the $0-1900 \mathrm{CE}$ period, in between the $-0.92^{\circ} \mathrm{C} 1000 \mathrm{yr}^{-1}$ value found with the NB2014 method and the $-0.47^{\circ} \mathrm{C} 1000 \mathrm{yr}^{-1}$ value found with the ECHAM scaling. The CPS method finds a slope of $-0.59^{\circ} \mathrm{C}$ $1000 \mathrm{yr}^{-1}$ for the period $0-1900 \mathrm{CE}$, very close to the borehole method.

Over all of Antarctica, we find a cooling trend of -0.26 to $-0.4^{\circ} \mathrm{C} 1000 \mathrm{yr}^{-1}$ between 0 and $1900 \mathrm{CE}$ across the various scaling approaches (Table 3 ). This trend is comparable in magnitude to the $-0.22 \pm 0.06^{\circ} \mathrm{C} 1000 \mathrm{yr}^{-1}$ found for the Arctic region (Kaufman et al., 2009). This trend was attributed to a decrease in June-August solar insolation due to precession of the equinoxes.

\subsubsection{Trends of the last 100 years in weighted reconstructions}

Studies based on individual ice cores have identified significant positive trends in the last century (Mulvaney et al., 2012; Steig et al., 2013). Similar to the findings for unweighted composites, significant warming trends in the weighted anomalies for the last 100 years (Table 4) are evident for the Antarctic Peninsula $\left(+2.65 \sigma 100 \mathrm{yr}^{-1}\right.$ with respect to the 1960-1990 CE normalization period), Dronning Maud Land Coast $\left(+2.51 \sigma 100 \mathrm{yr}^{-1}\right)$ and the West Antarctic Ice Sheet $\left(+1.17 \sigma 100 \mathrm{yr}^{-1}\right)$ regions. The trends in other regions are not significant (Table 4 ). In temperature units, the NB2014 method gives a scaling within $30 \%$ of ECHAM, while CPS is generally $50 \%$ lower (Table 4). Since $1900 \mathrm{CE}$, the reconstructions indicate that the Antarctic Peninsula has been warming by $1.14-2.87^{\circ} \mathrm{C} 100 \mathrm{yr}^{-1}$, the West Antarctic Ice Sheet by $0.46-1.32^{\circ} \mathrm{C} 100 \mathrm{yr}^{-1}$ and the Dronning Maud Land Coast by 0.59 to $1.33{ }^{\circ} \mathrm{C} 100 \mathrm{yr}^{-1}$. The borehole temperature adjustment needed to match the long-term trend leads to an overestimation of the 100-year trend in the WAIS region. Indeed, the same borehole temperature record finds a warming trend of $0.70^{\circ} \mathrm{C} 100 \mathrm{yr}^{-1}$ for the past

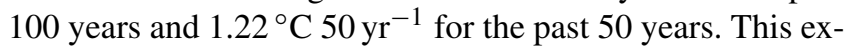
ample shows that a simple linear scaling cannot be valid for all timescales and that another approach will be needed to improve quantitative temperature reconstructions for Antarctica.

Despite these uncertainties on absolute scaling, our analyses underline that the sustained warming of the Antarctic Peninsula over the last century stands out as being a robust feature across all methods. Moreover, while the West Antarctic Ice Sheet and the Antarctic Peninsula regions have now seen reversal of the long-term cooling trend of the past 2000 years, this is not the case for the rest of the continent, where temperatures changes over the last century have not been significant (Fig. 4, Table 4).

\subsubsection{Significance of most recent 100-year trends relative to natural variability}

Finally, we assess how significant the trends in the most recent 100 years of the regional temperature reconstructions are relative to the range of all other 100-year trends in the reconstructions since $0 \mathrm{CE}$ (Fig. 6). The most recent 100year trend and its $( \pm 1 \sigma)$ uncertainty range are compared to the distribution of all other 100-year trends for that region. This assessment method uses overlapping trend analysis intervals that are not fully independent, but it captures the full range of possible trends in all 100-year intervals of the regional reconstructions. In this analysis, the significant recent positive trends for the Dronning Maud Land Coast and West Antarctic Ice Sheet do not emerge as unusual in the context of similar length trends of the last 2 millennia, consistent with the findings of Steig et al. (2013) based on the WAIS Divide ice core. However, the most recent 100-year warming of the Antarctic Peninsula is unusual compared to the range of natural century-scale warming trends of the last 2 millennia (Mulvaney et al., 2012). Thus, across all of our trend tests, the warming of the Antarctic Peninsula over the last century stands out as being robust to the binning of multiple isotopic anomaly records for the region, significant after weighting and scaling of the regional isotopic records to represent re- 
Table 4. Regression of the last 100-year slope based on the 5-year averages.

\begin{tabular}{|c|c|c|c|c|c|c|c|c|}
\hline \multirow[b]{2}{*}{ Geographic region } & \multirow[b]{2}{*}{$\begin{array}{l}\text { Start } \\
\text { date }\end{array}$} & \multirow[b]{2}{*}{$\begin{array}{l}\text { End } \\
\text { date }\end{array}$} & \multicolumn{2}{|c|}{ ECHAM } & \multicolumn{2}{|c|}{ NB2014 } & \multicolumn{2}{|c|}{ Borehole } \\
\hline & & & $\begin{array}{r}\text { Slope } \\
\left({ }^{\circ} \mathrm{C} 100 \mathrm{yr}^{-1}\right)\end{array}$ & $p$ value & $\begin{array}{r}\text { Slope } \\
\left({ }^{\circ} \mathrm{C} 100 \mathrm{yr}^{-1}\right)\end{array}$ & $p$ value & $\begin{array}{r}\text { Slope } \\
\left({ }^{\circ} \mathrm{C} 100 \mathrm{yr}^{-1}\right)\end{array}$ & $p$ value \\
\hline 1. East Antarctic Plateau & 1915 & 2010 & $-0.49 \pm 0.73$ & 0.174 & $-1.28 \pm 1.71$ & 0.133 & $\mathrm{NaN}$ & $\mathrm{NaN}$ \\
\hline 2. Wilkes Land Coast & 1915 & 1995 & $1.70 \pm-0.55$ & 0.034 & $0.47 \pm 0.60$ & 0.115 & $\mathrm{NaN}$ & $\mathrm{NaN}$ \\
\hline 3. Weddell Sea Coast & 1915 & 1995 & $-0.79 \pm 1.75$ & 0.351 & $-0.50 \pm 1.12$ & 0.351 & $\mathrm{NaN}$ & $\mathrm{NaN}$ \\
\hline 4. Antarctic Peninsula & 1915 & 2010 & $2.87 \pm 1.12$ & $<0.001$ & $1.99 \pm 0.75$ & $<0.001$ & $\mathrm{NaN}$ & $\mathrm{NaN}$ \\
\hline 5. West Antarctic Ice Sheet & 1915 & 2015 & $1.12 \pm 0.92$ & 0.020 & $0.97 \pm 0.75$ & 0.014 & $1.32 \pm 1.08$ & 0.020 \\
\hline 6. Victoria Land Coast & 1915 & 2005 & $-0.55 \pm 0.97$ & 0.247 & $-0.64 \pm 1.00$ & 0.195 & $\mathrm{NaN}$ & $\mathrm{NaN}$ \\
\hline 7. Dronning Maud Land Coast & 1915 & 2010 & $1.33 \pm 0.90$ & 0.006 & $0.98 \pm 0.73$ & 0.012 & $\mathrm{NaN}$ & $\mathrm{NaN}$ \\
\hline West Antarctica & 1915 & 2015 & $1.25 \pm 0.86$ & 0.007 & $1.12 \pm 0.62$ & 0.001 & $0.97 \pm 0.78$ & 0.019 \\
\hline East Antarctica & 1915 & 2010 & $0.09 \pm 0.58$ & 0.743 & $0.06 \pm 1.23$ & 0.924 & $\mathrm{NaN}$ & $\mathrm{NaN}$ \\
\hline \multirow[t]{2}{*}{ All Antarctica } & 1915 & 2015 & $0.79 \pm 0.82$ & 0.060 & $0.99 \pm 0.94$ & 0.040 & $0.21 \pm 0.38$ & 0.262 \\
\hline & \multicolumn{4}{|c|}{ Normalized } & \multicolumn{4}{|c|}{ CPS } \\
\hline Geographic region & & $\begin{array}{r}\text { Slope } \\
\left(\sigma 100 \mathrm{yr}^{-1}\right)\end{array}$ & $p$ value & & $\begin{array}{r}\text { Slope } \\
\left({ }^{\circ} \mathrm{C} 100 \mathrm{yr}^{-1}\right)\end{array}$ & $p$ value & $\begin{array}{r}\text { Start } \\
\text { date }\end{array}$ & $\begin{array}{l}\text { End } \\
\text { date }\end{array}$ \\
\hline 1. East Antarctic Plateau & & $-0.85 \pm 1.14$ & 0.133 & & $0.77 \pm 0.46$ & 0.004 & 1900 & 2000 \\
\hline 2. Wilkes Land Coast & & $1.08 \pm 1.37$ & 0.115 & & $0.05 \pm 0.49$ & 0.820 & 1900 & 1980 \\
\hline 3. Weddell Sea Coast & & $-1.10 \pm 2.45$ & 0.351 & & $-0.25 \pm 0.93$ & 0.544 & 1900 & 1980 \\
\hline 4. Antarctic Peninsula & & $2.65 \pm 0.99$ & $<0.001$ & & $1.14 \pm 0.60$ & 0.002 & 1900 & 2000 \\
\hline 5. West Antarctic Ice Sheet & & $1.17 \pm 0.90$ & 0.014 & & $0.46 \pm 0.63$ & 0.132 & 1900 & 2000 \\
\hline 6. Victoria Land Coast & & $-0.79 \pm 1.23$ & 0.195 & & $0.22 \pm 0.52$ & 0.364 & 1900 & 1990 \\
\hline 7. Dronning Maud Land Coast & & $2.51 \pm 1.88$ & 0.012 & & $0.59 \pm 0.61$ & 0.057 & 1900 & 1990 \\
\hline West Antarctica & & $1.50 \pm 0.83$ & 0.001 & & $0.60 \pm 0.61$ & 0.052 & 1900 & 2000 \\
\hline East Antarctica & & $0.04 \pm-0.85$ & 0.924 & & $0.43 \pm 0.33$ & 0.017 & 1900 & 2000 \\
\hline All Antarctica & & $0.72 \pm 0.68$ & 0.040 & & $0.43 \pm 0.32$ & 0.013 & 1900 & 2000 \\
\hline
\end{tabular}

gional temperature, and unusual compared with the range of natural century-scale temperature variability in this region over the last 2000 years. The companion Antarctica2k paper (Thomas et al., 2017) that examines snow accumulation across Antarctica over the last 1000 years also concludes that the most robust recent changes in snowfall are evident for the Antarctic Peninsula. Temperature and precipitation increases over the Antarctic Peninsula in recent decades have previously been linked to the SAM (Abram et al., 2014) and the effects of the coupling between SAM and El Niño-Southern Oscillation on the strength and position of the Amundsen Sea Low pressure and sea ice conditions offshore of West Antarctica and the Antarctic Peninsula (Thompson and Solomon, 2002; Ding et al., 2011; Thomas and Abram, 2016). The variability in these driving forcings over the past 2000 years could also explain part of the opposite regional climate variability that appears to be present on decadal and centennial scales between our reconstructions for the Antarctic Peninsula and the Victoria Land-Ross Sea regions.

Prior to this recent warming, which has been most significant for the Antarctic Peninsula region of Antarctica, long-term cooling is evident for many regions of Antarctica. In particular, it is the long-term cooling of the East Antarctic Plateau that emerges as significant in the weighted reconstructions and also robust across the distribution of contributing records in the unweighted composites. This is also in agreement with what was recently found by Hakim et al. (2016) using a data assimilation approach to identify a very strong $\mathrm{SH}$ cooling trend through the last 2000 years, up to about $1850 \mathrm{CE}$.

\subsection{Continent-scale temperature reconstructions}

Figure 7 shows the results obtained by applying the CPS method published in 2013 (PAGES 2k Consortium, 2013) to the expanded Antarctica2k database to reconstruct temperature across the whole Antarctic continent. A good agreement is observed between the new reconstruction and the previously published one (Fig. 7), on both annual and decadal scales ( $r=0.89$ and 0.91 , respectively). There is a slightly stronger negative temperature trend, which is related mainly to a slightly cooler temperature estimate for the 1600-1900 CE interval using the expanded database, in the new Antarctic continent-scale reconstruction. Figures in the Supplement similarly repeat this CPS comparison for the West Antarctica and East Antarctica regions and find similar agreement between the 2013 results and those using the expanded ice core database (Figs S11, S12 and S13).

Figure 8 shows the continental-scale (all of Antarctica), East Antarctica and West Antarctic temperature reconstruc- 


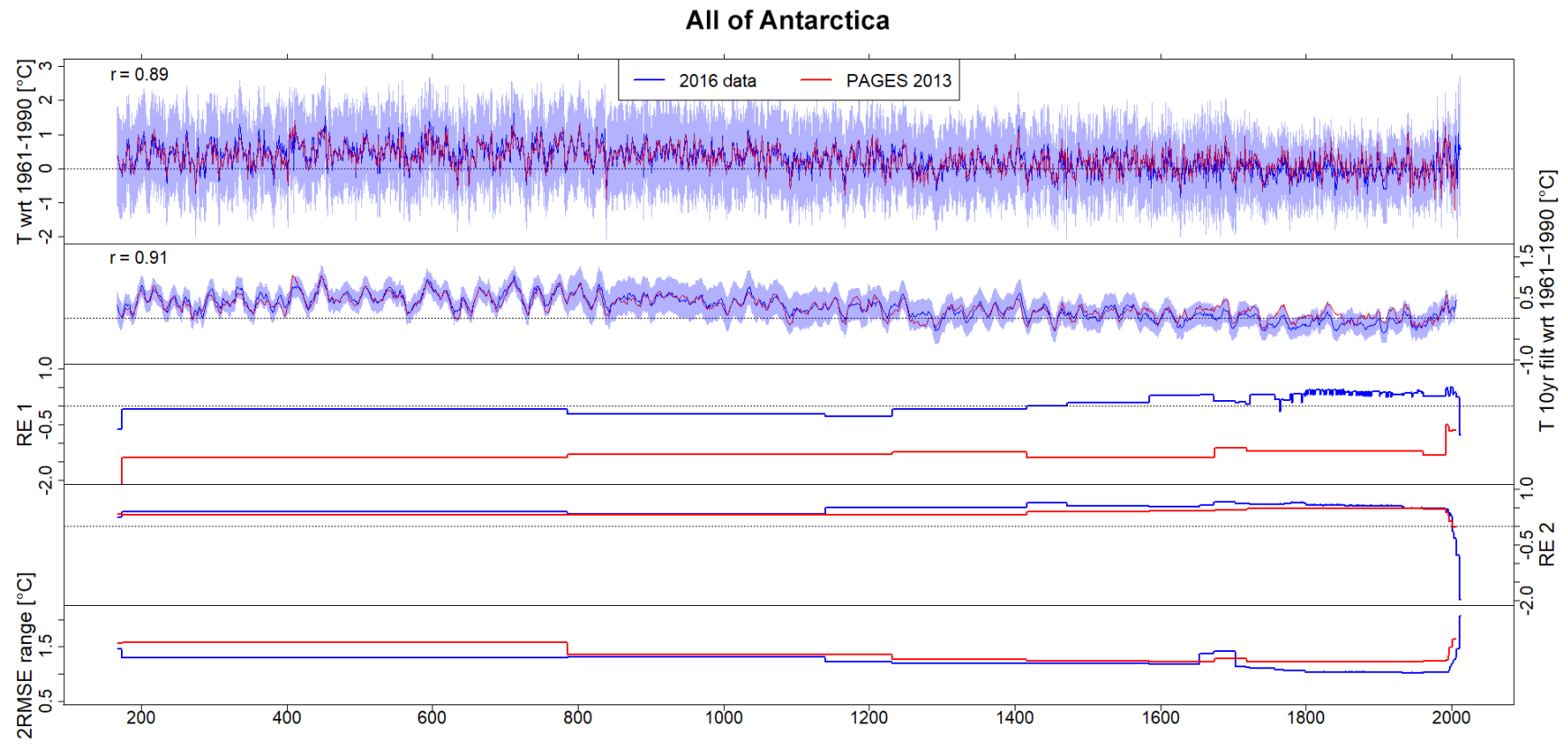

Figure 7. Comparison of CPS reconstructions of Antarctic mean temperatures over 167-2010 CE. Red shows results from PAGES 2k Consortium (2013). Blue shows updated results using the new ice core isotope data collection described herein and the NB2014 temperature target. Blue shading shows 2RMSE uncertainties of the updated reconstruction. The top panel shows unfiltered interannual reconstructions. The second panel shows the 10-year running mean of reconstructions. The third (fourth) panel shows reduction of error skill from a split calibration verification exercise using 1961-1976 for calibration (verification) and 1977-1991 for verification (calibration). The bottom panel shows the 2RMSE reconstruction uncertainty range.

tions that have been obtained from the different temperature scaling approaches in comparison with the CPS method. The period between 1200 and 1900 CE appears as the coldest interval in the East Antarctic reconstruction, and this is also reflected in the reconstruction on the whole continental scale. The warmest interval is identified between 300 and 1000 CE, especially for West Antarctica. The comparison between the CPS method and our new reconstruction methods shows a better agreement in East Antarctica than in West Antarctica when considering the ECHAM temperature scaling (Fig. 8). However, a better agreement between the CPS method and the temperature reconstruction obtained with the borehole scaling method is observed for West Antarctica. Note that ECHAM and NB2014 use two independent data sets for scaling the $\delta^{18} \mathrm{O}$ signal to temperature and that the difference between them is a measure of the uncertainty in the temperature reconstruction.

Over the period from 165 to $1900 \mathrm{CE}$ (the reconstruction interval of the 2013 PAGES 2k reconstruction for Antarctica), a cooling trend is common to all three broad-scale reconstruction regions and across all reconstruction methods (see Table S2). Cooling trends range between -0.21 and $-0.45^{\circ} \mathrm{C} 1000 \mathrm{yr}^{-1}$ for the ECHAM method and between -0.34 and $-0.53{ }^{\circ} \mathrm{C} 1000 \mathrm{yr}^{-1}$ for the borehole method. These values are in the range of those previously reported by the 2013 reconstruction (PAGES 2k Consortium, 2013) in which cooling trends of -0.18 and $-0.46{ }^{\circ} \mathrm{C} 1000 \mathrm{yr}^{-1}$ were calculated, for the same interval, for East and West Antarctica, respectively. By comparison, cooling trends of -0.25 and $-0.56{ }^{\circ} \mathrm{C} 1000 \mathrm{yr}^{-1}$ are calculated from the $10-$ year-binned data obtained with the same CPS methods but applied to this new database.

East Antarctica is one of the last places on the globe where the long-term cooling trend of the last millennium has not been inverted (PAGES 2k Consortium, 2013; Abram et al., 2016). This feature of delayed onset of industrial warming is clear in our reconstruction, but is not captured by climate models (PAGES 2k-PMIP3 group, 2015). Climate models are known to overestimate inter-hemispheric synchronicity (Neukom et al., 2014). The model-data mismatch may come from an overestimation of the response to external forcing in climate models, an underestimation of the role of internal ocean-atmosphere dynamics in models or incorrect inference from proxy data. This quantitative reconstruction will provide an important constraint on the forced vs. unforced nature of trends observed for the last century.

\subsection{Response to volcanic forcing}

The radiative forcing caused by major volcanic eruptions is known to drive hemispheric-scale cooling on subdecadal to decadal timescales (e.g. Sigl et al., 2015; Stoffel et al., 2015). Previous model-based assessments have suggested that the 

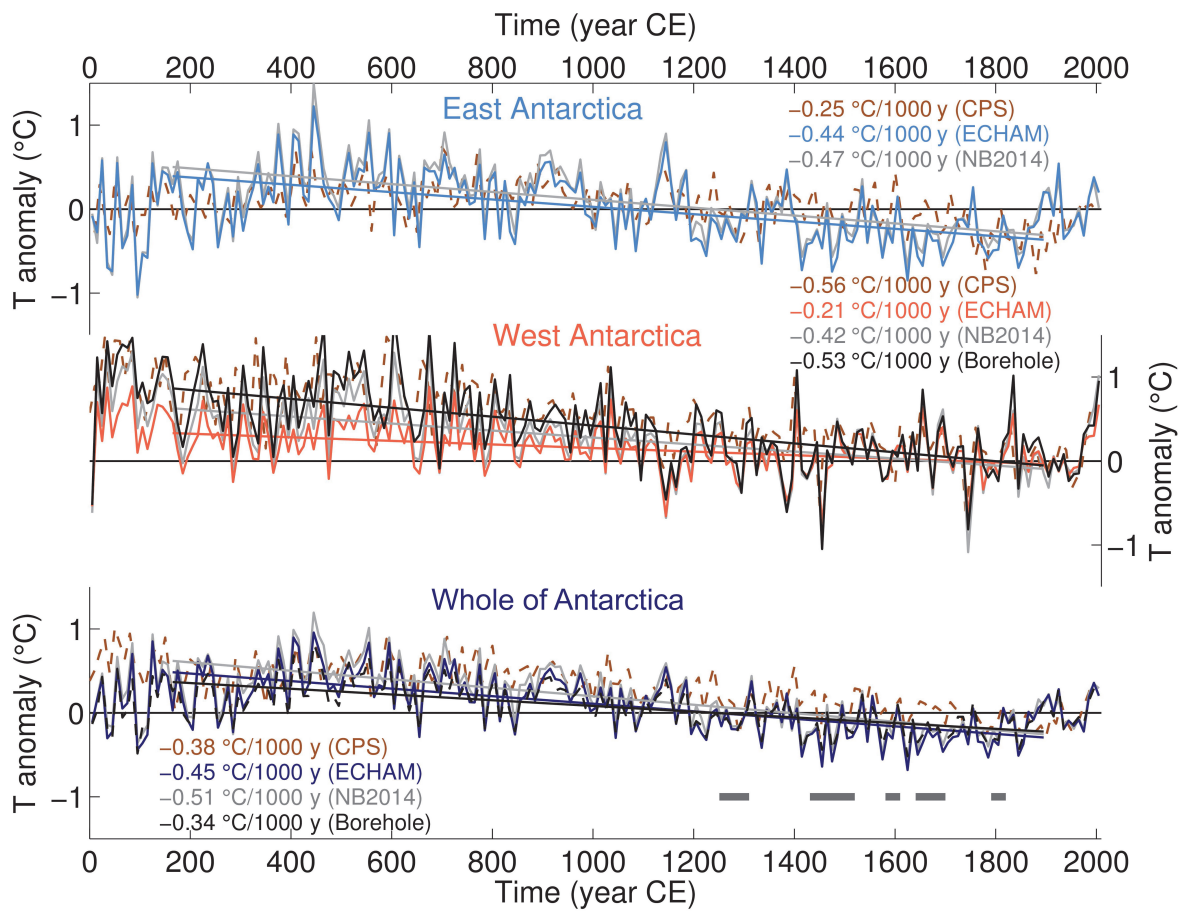

Figure 8. Composite temperature reconstructions ( $T$ anomalies in ${ }^{\circ} \mathrm{C}$ ) for East, West and the whole of Antarctica using 10 -year averages and the different temperature scaling approaches: dotted coloured lines for the CPS method (2013 method applied to the new database); grey lines for the method that uses the NB2014 variance for scaling (different weighting method compared to CPS); coloured lines for the method based on the correlation between annual mean regional $\delta^{18} \mathrm{O}$ and regional $T$ from ECHAM5-wiso forced by ERA-Interim; black lines for the method adjusted to match the temperature trend between 1000 and $1600 \mathrm{CE}$ based on borehole temperature measurements at WAIS Divide (Orsi et al., 2012). Linear trends are calculated between 165 and 1900 CE. The grey horizontal segments correspond to volcanic-solar downturn intervals as defined in PAGES 2k Consortium (2013) and corresponding to the following periods: 1251-1310 CE, 1431-1520 CE, 1581-1610 CE, 1641-1700 CE and 1791-1820 CE.
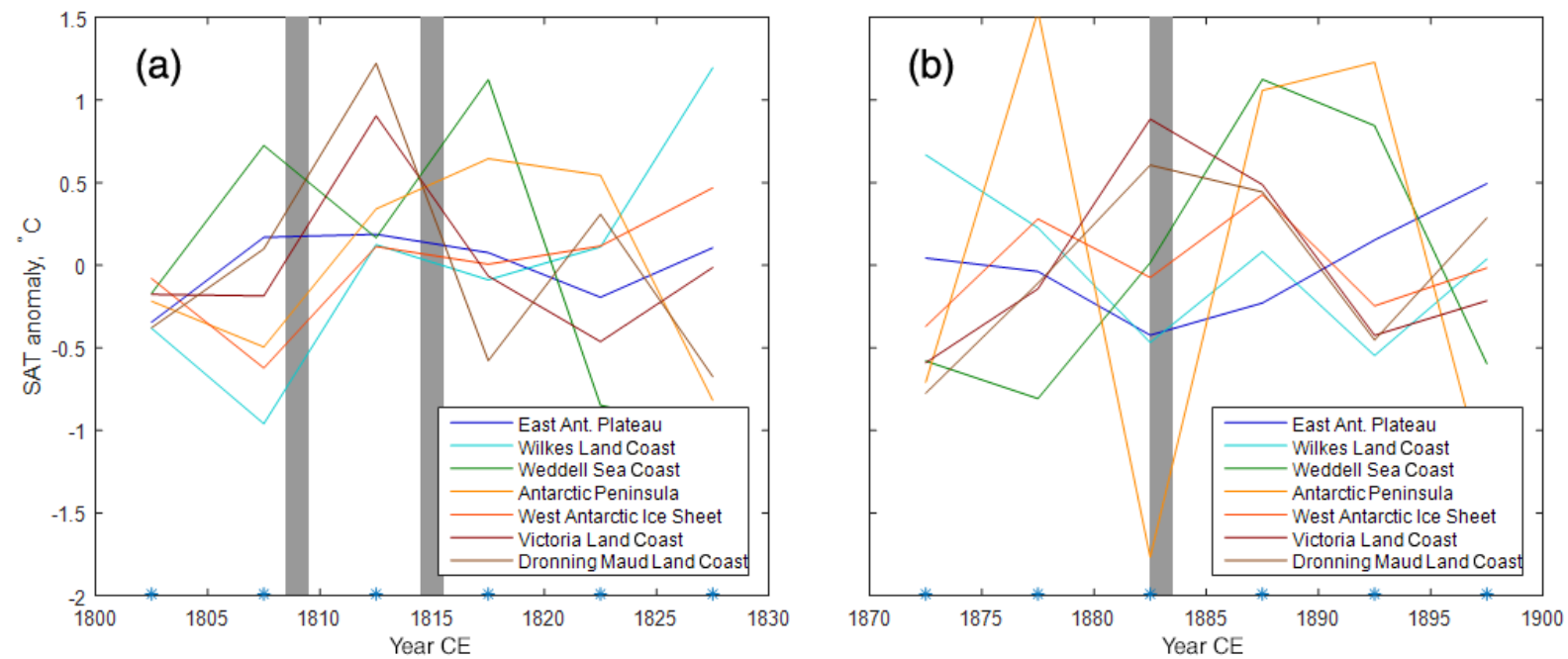

Figure 9. Reconstructed regional surface atmospheric temperature anomalies during the periods of 1802.5-1827.5 CE (a) and 1872.51897.5 CE (b) overlapping with the three major tropical volcanic eruptions of 1808/09, Mount Tambora 1815 and Krakatoa (1883). The reconstruction segments for each region were centred on the means of the corresponding intervals. Stars mark the bin centres of the reconstructions, and the years of the eruptions are highlighted in grey. 
long-term cooling trend over Antarctica during the 850$1850 \mathrm{CE}$ interval may be attributed to volcanic forcing of the climate (Goosse et al., 2012). Volcanic forcing may also affect atmospheric and oceanic dynamics, including modes of variability, causing substantial seasonal and regional variations in the climate footprint of volcanic forcing (e.g. Otterå et al., 2010; Schleussner et al., 2015; Ortega et al., 2015; Swingedouw et al., 2015). For example, the long-term cooling trend of the global oceans during the last 2 millennia has been attributed to the effects of short-term cooling from episodic eruptions being cycled into subsurface layers of the oceans (McGregor et al., 2015).

We use the composite reconstructions of Antarctic temperature anomalies to explore whether signatures and/or imprints of past major eruptions can be identified. Since different normalizations applied during the reconstruction procedure are not expected to affect a qualitative interpretation of the results, we present the analysis based on the reconstruction that fits 5-year annual $\delta^{18} \mathrm{O}$ to regional temperature anomalies from ECHAM5-wiso forced by ERA-Interim.

A robust identification of the climate impacts of volcanism from Antarctic ice cores faces a number of challenges. In addition to chronological uncertainties due to low accumulation and post-depositional alterations, processes other than local temperature may affect water stable isotopes in Antarctic precipitation, therefore making the detection of a temperature response to volcanic forcing more challenging. Finally, stacking the individual core records acts as a low-pass filter, suppressing the variability in the shorter, interannual timescales, thereby eliminating potentially short-lived cooling signals triggered by volcanic forcing.

Despite these limitations, it should be possible to record a volcanic cooling signal from well-dated cores from highaccumulation areas and/or around the time periods with clear markers of volcanic origin, widely used as precise age control points for constructing ice core chronologies. For example, the chemical fingerprints of two consecutive tropical eruptions of 1808/09 (Volcanic Explosivity Index (VEI) 67) and Mount Tambora 1815 (VEI 7) are detected in many Antarctic ice cores as a pronounced double peak in a number of measured ice parameters such as electrical conductivity or non-sea salt $\mathrm{SO}_{4}^{2-}$ profiles (Sigl et al., 2015).

Due to the aforementioned difficulties in the identification of a potential Antarctic temperature response to volcanic forcing, we restrict our analysis to the eruptions associated with the estimated strongest volcanic forcing, which are more likely to leave a clear footprint in ice core records. The highest-resolution reconstruction (5-year averages) is available for a period that experienced only three eruptions with a VEI of 6-7, namely the tropical eruptions of 1808/09, Mount Tambora 1815 and Krakatoa 1883. The signatures of the first two eruptions are commonly used as reference horizons when constructing the core chronologies. Due to a low number of replicates, we cannot use a superposed epoch analysis, commonly applied for detecting the signature of the cli- mate response to volcanic forcing (e.g. Fischer et al., 2007; Stoffel et al., 2015). Figure 9 simply displays the regional surface atmospheric temperature anomalies for the two periods centred at $1815 \mathrm{CE}$ and $1883 \mathrm{CE}$.

Following the Mount Tambora eruption, cooling is recorded in five out of our seven regional reconstructions, namely in the Dronning Maud Land Coast, Wilkes Land Coast, Victoria Land Coast, East Antarctic Plateau and possibly West Antarctic Ice Sheet regions. Following the 1808/09 eruption, cooling appears in three out of our seven regional reconstructions (West Antarctic Ice Sheet, Wilkes Land coast regions and to a lesser extent the Antarctic Peninsula). Following the Krakatoa eruption, regional cooling emerges for four out of seven regions (East Antarctic Plateau, Antarctic Peninsula, Wilkes Land coast and West Antarctic Ice Sheet regions). Potential response time lags should be interpreted with caution due to effects of the data binning procedure as well as age scale uncertainties.

Within the limitations associated with our reconstructions and with the small number of large eruptions in the time period studied, we can only report a lack of consistent panAntarctic cooling and a variable regional response. Such features have also been identified for the largest volcanic eruptions in the Northern Hemisphere (e.g. Guillet et al., 2017). Local negative anomalies following major eruptions may arise from non-temperature drivers of water stable isotope records and be artefacts of inconsistencies in chronologies; they may also reflect an actual regional cooling. Further studies will require a focus on ice core records with a solid chronological control and sufficient regional records to assess the common climatic signal from the deposition noise. Second-order isotopic parameters such as deuterium excess, which preserves a signal associated with moisture source characteristics, may also provide insights into the response of the Southern Ocean surface state to volcanic forcing.

This analysis represents only a preliminary attempt to assess the possible short-term climatic response of Antarctic climate to volcanic forcing, and we suggest that this is a good avenue for further detailed study using the expanded Antarctica2k isotope database assembled here.

\section{Conclusions and implications}

We have presented a new enlarged database of high- and low-resolution ice core water stable isotope records from Antarctica, which has been compiled in the framework of the PAGES Antarctica2k working group. To further develop our scientific understanding based on continent-scale reconstructions of Antarctic temperature, we define seven climatic regions based on our knowledge of the regional Antarctic climate and further supported by spatial correlation of temperature using the NB2014 reanalysis data. In our reconstructions of both regional- and continent-scale climate, we use 5- and 10-year-averaged data in order to limit our depen- 
dence on annually precise dating, which faces real problems, especially in interior Antarctica, due to the very low snow accumulation there. Similar conclusions are reached using different approaches (ECHAM, NB2014 and borehole methods), giving support to our temperature reconstructions. Furthermore, a replication of the CPS approach used in a previous continent-scale reconstruction but adapted to the new database also produces consistent results. The range of the values obtained from these four methods provides information on the uncertainties related to the temperature reconstructions on regional and continental scales.

Our new continent-scale reconstructions, based on the extended database, corroborate previously published findings for Antarctica from the PAGES 2k Consortium (2013): (1) temperatures over the Antarctic continent show an overall cooling trend during the period from 0 to $1900 \mathrm{CE}$, which appears strongest in West Antarctica, and (2) no continentscale warming of Antarctic temperature is evident in the last century.

The robust and significant long-term cooling trend of Antarctic-wide temperatures from 0 to $1900 \mathrm{CE}$ is also reflected in the broader East Antarctic and West Antarctic regions. In East Antarctica, the coldest interval occurs from 1200 to 1900 CE. During the same time period, five intervals of volcanic-solar downturns have been previously linked to cooling in temperature reconstructions for other continental regions (PAGES 2k Consortium, 2013). These intervals of negative radiative forcings are in agreement with our lower temperature estimates during this time (Fig. 8).

The absence of significant continent-scale warming of Antarctica over the last 100 years is in clear contrast with the significant industrial-era warming trends that are evident in reconstructions for all other continents (except Africa) and the tropical oceans (Abram et al., 2016). As noted in other studies (e.g. Abram et al., 2016; Jones et al., 2016) the absence of continent-scale warming over Antarctica is not in agreement with climate model simulations, which consistently produce a 20th century warming trend over Antarctica in response to greenhouse gas forcing. The high interannual climate variability with respect to the magnitude of climate trends over Antarctica, and the small number of ice core records that have contributed to previous continent-scale reconstructions of Antarctic temperature, have been suggested as possible sources for the lack of detection of continentscale warming trends in palaeoclimate records from Antarctica. However, we replicate this finding of a continent-scale absence of 20th century warming using our greatly expanded ice core database and with composites and reconstructions based on a range of methods. This suggests that the absence of continent-scale warming over Antarctica during the last century is a robust result and alternate reasons for datamodel divergences need to be investigated.

Despite the lack of significant warming over the last 100 years on the continent scale, there are three regions that show positive and significant isotopic and temperature trends: the Antarctic Peninsula, the West Antarctic Ice Sheet and the coastal Dronning Maud Land. However, currently only for the Antarctic Peninsula is the last 100-year trend unusual in the context of natural century-scale trends over the last 2000 years. Although, if sustained and significant warming of Dronning Maud Land Coast and the West Antarctic Ice Sheet continues during the coming decades (as would be expected based on climate model simulations), then these areas may soon also see the recent warming emerge as unusual in the context of natural variability. A companion paper (Thomas et al., 2017), which examines the snow accumulation rate variability over Antarctica during the last millennium, reaches the same conclusion, showing that in the Antarctic Peninsula region the late 20th century snowfall increase is unusual in the context of the past 300 years. The regional- to local-scale patterns of climate changes, and the processes that these illustrate, are another target for future research that could be explored using the new Antarctica2k database. Future work will also consider the comparison of the results obtained in this study with those by Thomas et al. (2017), assessing the snow accumulation rate variability in the same regions, with the aim of exploring a longstanding question about the relationship between temperature and precipitation in Antarctica.

Our new regional- and continent-scale reconstructions of Antarctic temperatures again highlight the urgent need to increase the spatial coverage of the sparse data for this continent with new temperature records, particularly focusing in the coastal areas. These regions are typically seen to be data-poor areas in our extended database. However, the coastal areas are also the places where high-resolution ice cores can be retrieved, where strong climatic differences can occur over relatively short distances, where there is some evidence for non-significant but emerging development of warming trends, where even small amounts of warming can rapidly move the local climate beyond the threshold and where surface melting of snow occurs, potentially leading to widespread impacts of any future Antarctic warming.

Data availability. The target data set of NB2014 is archived at http://polarmet.osu.edu/datasets/Antarctic_recon/. Table S1 (in the Supplement) contains the data citations, as well as the primary bibliographic reference, for each record used in this study. We used the URL links for existing published data from public repositories.

The regional- and continent-scale isotopic composites, including the statistical information for the 5- and 10-year unweighted composites, and temperature reconstructions generated during the current study and Table S1 are available in the NOAA World Data Center for Paleoclimatology (WDC Paleo) at the following link: https://www.ncdc.noaa.gov/paleo/study/22589.

The Supplement related to this article is available online at https://doi.org/10.5194/cp-13-1609-2017-supplement. 
Author contributions. BS led Phase 2 of the Antarctica2k project, and MAJC was data manager. The data analysis presented in this paper was carried out by NJA, AO, SG, RN and DD. BS, NJA and $\mathrm{AO}$ led the writing of the paper, with contributions by MAJC, SG, RN, VM-D, HG, DD and EJS. All authors contributed to discussions on the analysis design and paper.

Special issue statement. This article is part of the special issue "Climate of the past 2000 years: regional and trans-regional syntheses". It is not associated with a conference.

Acknowledgements. This paper is the Antarctic contribution to the international effort to characterize global climate variability during the last 2000 years, coordinated within the Past Global Changes PAGES 2k network working group (http://www.pages-igbp.org/ini/ $\mathrm{wg} / 2 \mathrm{k}$-network/intro) and the planning group International Partnership for Ice Core Science, IPICS (http://www.pages-igbp.org/ini/ end-aff/ipics/intro). We thank all of the scientists who made their ice core data available for this study.

This is a contribution to the PAGES $2 \mathrm{k}$ Network (through the Antarctica2k working group). Past Global Changes (PAGES) is supported by the US and Swiss National Science Foundations. Nerilie J. Abram acknowledges funding from the Australian Research Council through Discovery Project DP140102059. Barbara Stenni acknowledges funding from the PNRA (Italian Antarctic Research Programme) IPICS-2kyr-It project. Raphael Neukom is funded by the Swiss NSF (Ambizione grant PZ00P2_154802).

Edited by: Christian Turney

Reviewed by: two anonymous referees

\section{References}

Abram, N. J., Mulvaney, R., and Arrowsmith, C.: Environmental signals in a highly resolved ice core from James Ross Island, Antarctica, J. Geophys. Res.-Atmos., 116, D20116, https://doi.org/10.1029/2011JD016147, 2011.

Abram, N. J., Mulvaney, R., Wolff, E. W., Triest, J., Kipfstuhl, S., Trusel, L. D., Vimeux, F., Fleet, L., and Arrowsmith, C.: Acceleration of snow melt in an Antarctic Peninsula ice core during the twentieth century, Nat. Geosci., 6, 404-411, https://doi.org/10.1038/ngeo1787, 2013.

Abram, N. J., Mulvaney, R., Vimeux, F., Phipps, S. J., Turner, J., and England, M. H.: Evolution of the Southern Annular Mode during the past millennium, Nat. Clim. Change, 4, 564-569, https://doi.org/10.1038/NCLIMATE2235, 2014.

Abram, N. J., McGregor, H. V., Tierney, J. E., Evans, M. N., McKay, N. P., Kaufman, D. S., and the PAGES $2 \mathrm{k}$ Consortium: Early onset of industrial-era warming across the oceans and continents, Nature, 536, 411-418, https://doi.org/10.1038/nature19082, 2016.

Armour, K. C., Marshall, J., Scott, J. R., Donohoe, A., and Newsom, E. R.: Southern Ocean warming delayed by circumpolar upwelling and equatorward transport, Nat. Geosci., 9, 549-554, https://doi.org/10.1038/ngeo2731, 2016.
Bertler, N. A. N., Conway, H., Dahl-Jensen, D., Emanuelsson, D. B., Winstrup, M., Vallelonga, P. T., Lee, J. E., Brook, E. J., Severinghaus, J. P., Fudge, T. J., Keller, E. D., Baisden, W. T., Hindmarsh, R. C. A., Neff, P. D., Blunier, T., Edwards, R., Mayewski, P. A., Kipfstuhl, S., Buizert, C., Canessa, S., Dadic, R., Kjær, H. A., Kurbatov, A., Zhang, D., Waddington, E. D., Baccolo, G., Beers, T., Brightley, H. J., Carter, L., Clemens-Sewall, D., Ciobanu, V. G., Delmonte, B., Eling, L., Ellis, A. A., Ganesh, S., Golledge, N. R., Haines, S. A., Handley, M., Hawley, R. L., Hogan, C. M., Johnson, K. M., Korotkikh, E., Lowry, D. P., Mandeno, D., McKay, R. M., Menking, J. A., Naish, T. R., Noerling, C., Ollive, A., Orsi, A., Proemse, B. C., Pyne, A. R., Pyne, R. L., Renwick, J., Scherer, R. P., Semper, S., Simonsen, M., Sneed, S. B., Steig, E. J., Tuohy, A., Ulayottil Venugopal, A., Valero-Delgado, F., Venkatesh, J., Wang, F., Wang, S., Winski, D. A., Winton, V. H. L., Whiteford, A., Xiao, C., Yang, J., and Zhang, X.: The Ross Sea Dipole - Temperature, Snow Accumulation and Sea Ice Variability in the Ross Sea Region, Antarctica, over the Past 2700 Years, Clim. Past Discuss., https://doi.org/10.5194/cp-2017-95, in review, 2017.

Bonne, J.-L., Masson-Delmotte, V., Cattani, O., Delmotte, M., Risi, C., Sodemann, H., and Steen-Larsen, H. C.: The isotopic composition of water vapour and precipitation in Ivittuut, southern Greenland, Atmos. Chem. Phys., 14, 4419-4439, https://doi.org/10.5194/acp-14-4419-2014, 2014.

Bromwich, D. H., Nicolas, J. P., Monaghan, A. J., Lazzara, M. A., Keller, L. M., Weidner, G. A., and Wilson, A. B.: Central West Antarctica among the most rapidly warming regions on Earth, Nat. Geosci., 6, 139-145, https://doi.org/10.1038/ngeo1671, 2013.

Casado, M., Landais, A., Masson-Delmotte, V., Genthon, C., Kerstel, E., Kassi, S., Arnaud, L., Picard, G., Prie, F., Cattani, O., Steen-Larsen, H.-C., Vignon, E., and Cermak, P.: Continuous measurements of isotopic composition of water vapour on the East Antarctic Plateau, Atmos. Chem. Phys., 16, 8521-8538, https://doi.org/10.5194/acp-16-8521-2016, 2016.

Dee, D., Uppala, S., Simmons, A., Berrisford, P., Poli, P., Kobayashi, S., Andrae, U., Balmaseda, M., Balsamo, G., and Bauer, P.: The ERA-Interim reanalysis: configuration and performance of the data assimilation system, Q. J. Roy. Meteor. Soc., 137, 553-597, 2011.

Ding, Q., Steig, E. J., Battisti, D. S., and Küttel, M.: Winter warming in West Antarctica caused by central tropical Pacific warming, Nat. Geosci., 4, 398-403, https://doi.org/10.1038/ngeo1129, 2011.

Dittmann, A., Schlosser, E., Masson-Delmotte, V., Powers, J. G., Manning, K. W., Werner, M., and Fujita, K.: Precipitation regime and stable isotopes at Dome Fuji, East Antarctica, Atmos. Chem. Phys., 16, 6883-6900, https://doi.org/10.5194/acp16-6883-2016, 2016.

Ekaykin, A. A., Lipenkov, V. Y., Kuzmina, I. N., Petit, J. R., Masson-Delmotte, V., and Johnsen, S. J.: The changes in isotope composition and accumulation of snow at Vostok Station, East Antarctica, over the past 200 years, Ann. Glaciol., 39, 569-575, 2004.

Ekaykin, A. A., Kozachek, A. V., Lipenkov, V. Y., and Shibaev, Y. A.: Multiple climate shifts in the Southern Hemisphere over the past three centuries based on central Antarc- 
tic snow pits and core studies, Ann. Glaciol., 55, 259-266, https://doi.org/10.3189/201AoG66A189, 2014.

Emanuelsson, D. B., Bertler, N. A. N., Neff, P., Renwick, J., Markle, B., Baisden, W. T., Keller, E.: The role of AmundsenBellingshausen Sea anticyclonic circulation in forcing marine air intrusions into West Antarctica, Clim. Dynam., CLDY-D-1600858, submitted, 2017.

Fegyveresi, J. M., Alley, R. B., Spencer, M. K., Fitzpatrick, J. J., Steig, E. J., White, J. W. C., McConnell, J. R., and Taylor, K. C.: Late-Holocene climate evolution at the WAIS Divide site, West Antarctica: bubble number-density estimates, J. Glaciol., 57, 629-638, 2011.

Fernandoy, F., Meyer, H., Oerter, H., Wilhelms, F., Graf, W., and Schwander, J.: Temporal and spatial variation of stable-isotope ratios and accumulation rates in the hinterland of Neumayer Station, East Antarctica, J. Glaciol., 56, 673-687, 2010.

Fernandoy, F., Meyer, H., and Tonelli, M.: Stable water isotopes of precipitation and firn cores from the northern Antarctic Peninsula region as a proxy for climate reconstruction, The Cryosphere, 6 , 313-330, https://doi.org/10.5194/tc-6-313-2012, 2012.

Fischer, E. M., Luterbacher, J., Zorita, E., Tett, S. F. B., Casty, C., and Wanner, H.: European climate response to tropical volcanic eruptions over the last half millennium, Geophys. Res. Lett., 34, L05707, https://doi.org/10.1029/2006GL027992, 2007.

Flato, G., Marotzke, J., Abiodun, B., Braconnot, P., Chou, S. C., Collins, W., Cox, P., Driouech, F., Emori, S., Eyring, V., Forest, C., Gleckler, P., Guilyardi, E., Jakob, C., Kattsov, V., Reason, C., and Rummukainen, M.: Evaluation of climate models, in: Climate Change 2013: The Physical Science Basis. Contribution of Working Group I to the Fifth Assessment Report of the Intergovernmental Panel on Climate Change, edited by: Stocker, T. F., Qin, D., Plattner, G.-K., Tignor, M., Allen, S. K., Boschung, J., Nauels, A., Xia, Y., Bex, V., Midgley, P. M., Cambridge University Press, Cambridge, UK and New York, NY, USA, 2013.

Frezzotti, M., Urbini, S., Proposito, M., Scarchilli, C., and Gandolfi, S.: Spatial and temporal variability of surface mass balance near Talos Dome, East Antartica, J. Geophys. Res.-Earth, 112, F02032, https://doi.org/10.1029/2006JF000638, 2007.

Goosse, H., Braida, M., Crosta, X., Mairesse, A., MassonDelmotte, V., Mathiot, P., Neukom, R., Oerter, H., Philippon, G., Renssen, H., Stenni, B., van Ommen, T., and Verleyen, E.: Antarctic temperature changes during the last millennium: evaluation of simulations and reconstructions, Quaternary Sci. Rev., 55, 75-90, https://doi.org/10.1016/j.quascirev.2012.09.003, 2012.

Goosse, H.: Reconstructed and simulated temperature asymmetry between continents in both hemispheres over the last centuries. Clim. Dynam., 48, 1483-1501, https://doi.org/10.1007/s00382016-3154-z, 2017.

Goursaud, S., Masson-Delmotte, V., Favier, V., Preunkert, S., Fily, M., Gallée, H., Jourdain, B., Legrand, M., Magand, O., Minster, B., and Werner, M.: A 60-year ice-core record of regional climate from Adélie Land, coastal Antarctica, The Cryosphere, 11, 343 362, https://doi.org/10.5194/tc-11-343-2017, 2017.

Guillet, S., Corona, C., Stoffel, M., Khodri, M., Lavigne, F., Ortega, P., Eckert, N., Sielenou, P. D., Daux, V., Churakova (Sidorova), O. V., Davi, N., Edouard, J. L., Zhang, Y., Luckman, B. H., Myglan, V. S., Guiot, J., Beniston, M., Masson-Delmotte, V., and Oppenheimer, C.: Climate response to the Samalas volcanic eruption in 1257 revealed by proxy records, Nat. Geosci., 10, 123-128, https://doi.org/10.1038/ngeo2875, 2017.

Hakim, G. J., Emile-Geay, J., Steig, E. J., Noone, D., Anderson, D. M., Tardif, R., Steiger, N., and Perkins, W. A.: The last millennium climate reanalysis project: framework and first results, J. Geophys. Res.-Atmos., 121, 6745-6764, https://doi.org/10.1002/2016JD024751, 2016.

Hoffmann, G., Werner, M., and Heimann, M.: Water isotope module of the ECHAM atmospheric general circulation model: a study on timescales from days to several years, J. Geophys. Res.Atmos., 103, 16871-16896, 1998.

Hoshina, Y., Fujita, K., Nakazawa, F., Iizuka, Y., Miyake, T., Hirabayashi, M., Kuramoto, T., Fujita, S., and Motoyama, H.: Effect of accumulation rate on water stable isotopes of near-surface snow in inland Antarctica, J. Geophys. Res.-Atmos., 119, 274 283, https://doi.org/10.1002/2013JD020771, 2014.

Jones, P. D., Briffa, K. R., Osborn, T. J., Lough, J. M., van Ommen, T. D., Vinther, B. M., Luterbacher, J., Wahl, E. R., Zwiers, F. W., Mann, M. E., Schmidt, G. A., Ammann, C. M., Buckley, B. M., Cobb, K. M., Esper, J., Goosse, H., Graham, N., Jansen, E., Kiefer, T., Kull, C., Küttel, M., Mosley-Thompson, E., Overpeck, J. T., Riedwyl, N., Schulz, M., Tudhope, A. W., Villalba, R., Wanner, H., Wolff, E., and Xoplaki, E.: High-resolution palaeoclimatology of the last millennium: a review of current status and future prospects, The Holocene, 19, 3-49, https://doi.org/10.1177/0959683608098952, 2009.

Jones, J. M., Gille, S. T., Goosse, H., Abram, N. J., Canziani, P. O., Charman, D. J., Clem, K. R., Crosta, X., de Lavergne, C., Eisenman, I., England, M. H., Fogt, R. L., Frankcombe, L. M., Marshall, G. J., Masson-Delmotte, V., Morrison, A. K., Orsi, A. J., Raphael, M. N., Renwick, J. A., Schneider, D. P., Simpkins, G. R., Steig, E. J., Stenni, B., Swingedouw, D., and Vance, T. R.: Assessing recent trends in high-latitude Southern Hemisphere surface climate, Nat. Clim. Change, 6, 917-926, https://doi.org/10.1038/NCLIMATE3103, 2016.

Jouzel, J.: Water stable isotopes: atmospheric composition and applications in polar ice core studies, in: Treatise on Geochemistry, 2nd Ed., Vol. 5, The Atmosphere, edited by: Keeling, R. and Russel, L., Elsevier, 213-256, https://doi.org/10.1016/B9780-08-095975-7.00408-3, 2014.

Jouzel, J. and Merlivat, L.: Deuterium and oxygen 18 in precipitation: modeling of the isotopic effects during snow formation, $\mathbf{J}$ Geophys. Res.-Atmos., 89, 11749-11757, 1984.

Kaufman, D. S., Schneider, D. P., McKay, N. P., Ammann, C. M., Bradley, R. S., Briffa, K. R., Miller, G. H., Otto-Bliesner, B. L., Overpeck, J. T., Vinther, B. M., and Lakes, A.: Recent warming reverses long-term Arctic cooling, Science, 325, 1236-1239, 2009.

Küttel, M., Steig, E. J., Ding, Q., Monaghan, A. J., and Battisti, D. S.: Seasonal climate information preserved in West Antarctic ice core water isotopes: relationships to temperature, large-scale circulation, and sea ice, Clim. Dynam., 39, 18411857, https://doi.org/10.1007/s00382-012-1460-7, 2012.

Masson-Delmotte, V., Hou, S., Ekaykin, A., Jouzel, J., Aristarain, A., Bernardo, R., Bromwich, D., Cattani, O., Delmotte, M., Falourd, S., Frezzotti, M., Gallée, H., Genoni, L., Isaksson, E., Landais, A., Helsen, M., Hoffman, G., Lopez, J., 
Morgan, V., Motoyama, H., Noone, D., Oerter, H., Petit, J., Royer, A., Uemura, R., Schmidt, G., Schlosser, E., Simões, J., Steig, E., Stenni, B., Stievenard, M., Van den Breoke, M., Van de Wak, R., Van de Berg, W., Vimeux, F., and White, J.: A review of Antarctic surface snow isotopic composition: observations, atmospheric circulation, and isotopic modeling, J. Climate, 21, 3359-3387, https://doi.org/10.1175/2007JCLI2139.1, 2008.

Masson-Delmotte, V., Buiron, D., Ekaykin, A., Frezzotti, M., Gallée, H., Jouzel, J., Krinner, G., Landais, A., Motoyama, H., Oerter, H., Pol, K., Pollard, D., Ritz, C., Schlosser, E., Sime, L. C., Sodemann, H., Stenni, B., Uemura, R., and Vimeux, F.: A comparison of the present and last interglacial periods in six Antarctic ice cores, Clim. Past, 7, 397-423, https://doi.org/10.5194/cp-7-397-2011, 2011.

McGregor, H. V., Evans, M. N., Goosse, H., Leduc, G., Martrat, B., Addison, J. A., Mortyn, P. G., Oppo, D. W., Seidenkrantz, M.S., Sicre, M.-A., Phipps, S. J., Selvaraj, K., Thirumalai, K., Filipsson, H. L., and Ersek, V.: Robust global ocean cooling trend for the pre-industrial Common Era, Nat. Geosci., 8, 671-677, https://doi.org/10.1038/NGEO2510, 2015.

Mulvaney, R., Abram, N. J., Hindmarsh, R. C. A., Arrowsmith, C., Fleet, L., Triest, J., Sime, L. C., Alemany, O., and Foord, S.: Recent Antarctic Peninsula warming relative to Holocene climate and ice-shelf history, Nature, 489, 141-144, https://doi.org/10.1038/nature11391, 2012.

Neff, P. D. and Bertler, N. A. N.: Trajectory modeling of modern dust transport to the Southern Ocean and Antarctica, J. Geophys. Res.-Atmos., 120, 9303-9322, https://doi.org/10.1002/2015JD023304, 2015.

Neukom, R., Gergis, J., Karoly, D. J., Wanner, H., Curran, M., Elbert, J., González-Rouco, F., Linsley, B. K., Moy, A. D., Mundo, I., Raible, C. C., Steig, E. J., van Ommen, T., Vance, T., Villalba, R., Zinke, J., and Frank, D.: Inter-hemispheric temperature variability over the past millennium, Nat. Clim. Change, 4, 362-367, https://doi.org/10.1038/nclimate2174, 2014.

Nicolas, J. P. and Bromwich, D. H.: New reconstruction of antarctic near-surface temperatures: multidecadal trends and reliability of global reanalyses, J. Climate, 27, 8070-8093, https://doi.org/10.1175/JCLI-D-13-00733.1, 2014.

Orsi, A. J., Cornuelle, B. D., and Severinghaus, J. P.: Little Ice Age cold interval in West Antarctica: evidence from borehole temperature at the West Antarctic Ice Sheet (WAIS) Divide, Geophys. Res. Lett., 39, L09710, https://doi.org/10.1029/2012GL051260, 2012.

Ortega, P., Lehner, F., Swingedouw, D., Masson-Delmotte, V., Raible, C. C., Casado, M., and Yiou, P.: A model-tested North Atlantic Oscillation reconstruction for the past millennium, Nature, 523, 71-74, https://doi.org/10.1038/nature14518, 2015.

Otterå, O. H., Bensen, M., Drange, H., and Suo, L.: External forcing as a metronome for Atlantic multidecadal variability, Nat. Geosci., 3, 688-694, https://doi.org/10.1038/NGEO955, 2010.

PAGES 2k Consortium: Continental-scale temperature variability during the past two millennia, Nat. Geosci., 6, 339-346, Published online 21 April 2013, https://doi.org/10.1038/NGEO1797, 2013.

PAGES 2k Consortium: A global multiproxy database for temperature reconstructions of the Common Era, Sci. Data, 4, 170088, https://doi.org/10.1038/sdata.2017.88, 2017.
PAGES 2k-PMIP3 group: Continental-scale temperature variability in PMIP3 simulations and PAGES $2 \mathrm{k}$ regional temperature reconstructions over the past millennium, Clim. Past, 11, 16731699, https://doi.org/10.5194/cp-11-1673-2015, 2015.

Plummer, C. T., Curran, M. A. J., van Ommen, T. D., Rasmussen, S. O., Moy, A. D., Vance, T. R., Clausen, H. B., Vinther, B. M., and Mayewski, P. A.: An independently dated 2000-yr volcanic record from Law Dome, East Antarctica, including a new perspective on the dating of the 1450s CE eruption of Kuwae, Vanuatu, Clim. Past, 8, 1929-1940, https://doi.org/10.5194/cp8-1929-2012, 2012.

Ritter, F., Steen-Larsen, H. C., Werner, M., Masson-Delmotte, V., Orsi, A., Behrens, M., Birnbaum, G., Freitag, J., Risi, C., and Kipfstuhl, S.: Isotopic exchange on the diurnal scale between near-surface snow and lower atmospheric water vapor at Kohnen station, East Antarctica, The Cryosphere, 10, 16471663, https://doi.org/10.5194/tc-10-1647-2016, 2016.

Roeckner, E., Bäuml, G., Bonaventura, L., Brokopf, R., Esch, M., Giorgetta, M., Hagemann, S., Kirchner, I., Kornblueh, L., and Manzini, E.: The atmospheric general circulation model ECHAM 5. PART I: Model description, Report 349, MaxPlanck-Institut für Meteorologie, Hamburg, 2003.

Schleussner, C. F., Divine, D. V., Donges, J. F., Miettinen, A., and Donner, R. V.: Indications for a North Atlantic ocean circulation regime shift at the onset of the Little Ice Age, Clim. Dynam., 45, 3623-3633, https://doi.org/10.1007/s00382-015-2561-x, 2015.

Schlosser, E., Reijmer, C., Oerter, H., and Graf, W.: The influence of origin of precipitation on the $\delta^{18} \mathrm{O}-\mathrm{T}$ relationship at Neumayer Station, Ekströmisen, Antarctica, Ann. Glaciol., 39, 41-48, 2004.

Schlosser, E., Reijmer, C., Oerter, H., and Graf, W.: The influence of origin of precipitation on the $\delta^{18} \mathrm{O}$-T relationship at Neumayer Station, Ekströmisen, Antarctica, Ann. Glaciol., 39, 41-48, 2004.

Schmidt, G. A., LeGrande, A. N., and Hoffmann, G.: Water isotope expressions of intrinsic and forced variability in a coupled ocean-atmosphere model, J. Geophys. Res.-Atmos., 112, D10103, https://doi.org/10.1029/2006JD007781, 2007.

Schneider, D. P., Steig, E. J., and van Ommen, T.: Interpretation of high resolution ice core stable isotope records from Antarctica: towards interannual climate reconstruction, Ann. Glaciol., 41, 63-70, 2005.

Schneider, D. P., Steig, E. J., van Ommen, T. D., Dixon, D. A., Mayewski, P. A., Jones, J. M., and Bitz, C. M.: Antarctic temperatures over the past two centuries from ice cores, Geophys. Res. Lett., 33, L16707, https://doi.org/10.1029/2006GL027057, 2006.

Sigl, M., McConnell, J. R., Toohey, M., Curran, M., Das, S. B., Edwards, R., Isaksson, E., Kawamura, K., Kipfstuhl, S., Krüger, K., Layman, L., Maselli, O. J., Motizuki, Y., Motoyama, H., Pasteris, D. R., and Severi, M.: Insights from Antarctica on volcanic forcing during the Common Era, Nat. Clim. Change, 4, 693-697, https://doi.org/10.1038/NCLIMATE2293, 2014.

Sigl, M., Winstrup, M., McConnell, J. R., Welten, K. C., Plunkett, G., Ludlow, F., Büntgen, U., Caffee, M., Chellman, N., Dahl-Jensen, D., Fischer, H., Kipfstuhl, S., Kostick, C., Maselli, O. J., Mekhaldi, F., Mulvaney, R., Muscheler, R., Pasteris, D. R., Pilcher, J. R., Salzer, M., Schüpbach, S., Steffensen, J. P., Vinther, B. M., and Woodruff, T. E.: Timing and climate forcing of volcanic eruptions for the past 2500 years, Nature, 523, 543-549, 2015. 
Sigl, M., Fudge, T. J., Winstrup, M., Cole-Dai, J., Ferris, D., McConnell, J. R., Taylor, K. C., Welten, K. C., Woodruff, T. E., Adolphi, F., Bisiaux, M., Brook, E. J., Buizert, C., Caffee, M. W., Dunbar, N. W., Edwards, R., Geng, L., Iverson, N., Koffman, B., Layman, L., Maselli, O. J., McGwire, K., Muscheler, R., Nishiizumi, K., Pasteris, D. R., Rhodes, R. H., and Sowers, T. A.: The WAIS Divide deep ice core WD2014 chronology Part 2: Annual-layer counting (0-31 ka BP), Clim. Past, 12, 769786, https://doi.org/10.5194/cp-12-769-2016, 2016.

Sime, L. C., Marshall, G. J., Mulvaney, R., and Thomas, E. R.: Interpreting temperature information from ice cores along the Antarctic Peninsula: ERA40 analysis, Geophys. Res. Lett., 36, L18801, https://doi.org/10.1029/2009GL038982, 2009.

Sodemann, H. and Stohl, A.: Asymmetries in the moisture origin of Antarctic precipitation, Geophys. Res. Lett., 36, L22803, https://doi.org/10.1029/2009GL040242, 2009.

Steen-Larsen, H. C., Masson-Delmotte, V., Hirabayashi, M., Winkler, R., Satow, K., Prié, F., Bayou, N., Brun, E., Cuffey, K. M., Dahl-Jensen, D., Dumont, M., Guillevic, M., Kipfstuhl, S., Landais, A., Popp, T., Risi, C., Steffen, K., Stenni, B., and Sveinbjörnsdottír, A. E.: What controls the isotopic composition of Greenland surface snow?, Clim. Past, 10, 377-392, https://doi.org/10.5194/cp-10-377-2014, 2014

Steen-Larsen, H. C., Risi, C., Werner, M., Yoshimura, K., and Masson-Delmotte, V.: Evaluating the skills of isotope-enabled general circulation models against in situ atmospheric water vapor isotope observations, J. Geophys. Res.-Atmos., 122, 246263, https://doi.org/10.1002/2016JD025443, 2017.

Steig, E. J., Schneider, D. P., Rutherford, S. D., Mann, M. E., Comiso, J. C., and Shindell, D. T.: Warming of the Antarctic icesheet surface since the 1957 International Geophysical Year, Nature, 457, 459-462, https://doi.org/10.1038/nature07669, 2009.

Steig, E. J., Ding, Q., White, J. W. C., Küttel, M., Rupper, S. B., Neumann, T. A., Neff, P. D., Gallant, A. J. E., Mayewski, P. A., Taylor, K. C., Hoffmann, G., Dixon, D. A., Schoenemann, S. W., Markle, B. R., Fudge, T. J., Schneider, D. P., Schauer, A. J., Teel, R. P., Vaughn, B. H., Burgener, L., Williams, J., and Korotkikh, E.: Recent climate and ice-sheet changes in West Antarctica compared with the past 2000 years, Nat. Geosci., 6, 372-375, https://doi.org/10.1038/ngeo1778, 2013.

Stenni, B., Scarchilli, C., Masson-Delmotte, V., Schlosser, E., Ciardini, V., Dreossi, G., Grigioni, P., Bonazza, M., Cagnati, A., Karlicek, D., Risi, C., Udisti, R., and Valt, M.: Three year monitoring of stable isotopes of precipitation at Concordia Station, East Antarctica, The Cryosphere, 10, 2415-2428, https://doi.org/10.5194/tc-10-2415-2016, 2016.

Stoffel, M., Khodri, M., Corona, C., Guillet, S., Poulain, V., Bekki, S., Guiot, J., Luckman, B., Oppenheimer, C., Lebas, N., Beniston, M., and Masson-Delmotte, V.: Estimates of volcanic-induced cooling in the Northern Hemisphere over the past 1500 years, Nat. Geosci., 8, 784-788, https://doi.org/10.1038/ngeo2526, 2015.

Swingedouw, D., Ortega, P., Mignot, J., Guilyardi, E., MassonDelmotte, V., Butler, P. G., Khodri, M., and Séférian, R.: Bidecadal North Atlantic ocean circulation variability controlled by timing of volcanic eruptions, Nat. Commun., 6, 6545, https://doi.org/10.1038/ncomms7545, 2015.

Thomas, E. R. and Abram, N. J.: Ice core reconstruction of sea ice change in the Amundsen-Ross Seas since 1702 A.D., Geophys. Res. Lett., 43, 5309-5317, https://doi.org/10.1002/2016GL068130, 2016.

Thomas, E. R. and Bracegirdle, T. J.: Precipitation pathways for five new ice core sites in Ellsworth Land, West Antarctica, Clim. Dynam., 44, 2067-2078, https://doi.org/10.1007/s00382-014-22136, 2015 .

Thomas, E. R., Dennis, P. F., Bracegirdle, T. J., and Franzke, C.: Ice core evidence for significant 100 year regional warming on the Antarctic Peninsula, Geophys. Res. Lett., 36, L20704, https://doi.org/10.1029/2009GL040104, 2009.

Thomas, E. R., Bracegirdle, T. J., Turner, J., and Wolff, E. W.: A 308 year record of climate variability in West Antarctica, Geophys. Res. Lett., 40, 5492-5496, https://doi.org/10.1002/2013GL057782, 2013.

Thomas, E. R., van Wessem, J. M., Roberts, J., Isaksson, E., Schlosser, E., Fudge, T. J., Vallelonga, P., Medley, B., Lenaerts, J., Bertler, N., van den Broeke, M. R., Dixon, D. A., Frezzotti, M., Stenni, B., Curran, M., and Ekaykin, A. A.: Regional Antarctic snow accumulation over the past 1000 years, Clim. Past, 13, 1491-1513, https://doi.org/10.5194/cp-13-1491-2017, 2017.

Thompson, D. W. J. and Solomon, S.: Interpretation of recent Southern Hemisphere climate change, Science, 296, 895-899, https://doi.org/10.1126/science.1069270, 2002.

Thompson, D. W. J., Solomon, S., Kushner, P. J., England, M. H., Grise, K. M., and Karoly, D. J.: Signatures of the Antarctic ozone hole in Southern Hemisphere surface climate change, Nat. Geosci., 4, 741-749, https://doi.org/10.1038/ngeo1296, 2011.

Touzeau, A., Landais, A., Stenni, B., Uemura, R., Fukui, K., Fujita, S., Guilbaud, S., Ekaykin, A., Casado, M., Barkan, E., Luz, B., Magand, O., Teste, G., Le Meur, E., Baroni, M., Savarino, J., Bourgeois, I., and Risi, C.: Acquisition of isotopic composition for surface snow in East Antarctica and the links to climatic parameters, The Cryosphere, 10, 837-852, https://doi.org/10.5194/tc-10-837-2016, 2016.

Uppala, S. M., Kållberg, P., Simmons, A., Andrae, U., Bechtold, V. d., Fiorino, M., Gibson, J., Haseler, J., Hernandez, A., and Kelly, G.: The ERA-40 re-analysis, Q. J. Roy. Meteor. Soc., 131, 2961-3012, 2005.

Wang, Y., Ding, M., van Wessem, J. M., Schlosser, E., Altnau, S., van den Broeke, M. R., Lenaerts, J. T. M., Thomas, E. R., Isaksson, E., Wang, J., and Sun, W.: A comparison of Antarctic Ice Sheet surface mass balance from atmospheric climate models and in situ observations, J. Climate, 29, 5317-5337, https://doi.org/10.1175/JCLI-D-15-0642.1, 2016.

van Ommen, T. D. and Morgan, V. I.: Calibrating the ice core paleothermometer using seasonality, J. Geophys. Res.-Atmos., 102, 9351-9357, 1997.

Van Wessem, J. M., Reijmer, C. H., Morlighem, M., Mouginot, J., Rignot, E., Medley, B., and Van Meijgaard, E.: Improved representation of East Antarctic surface mass balance in a regional atmospheric climate model, J. Glaciol., 60, 761-770, https://doi.org/10.3189/2014JoG14J051, 2014.

Werner, M., Heimann, M., and Hoffmann, G.: Isotopic composition and origin of polar precipitation in present and glacial climate simulations, Tellus B, 53, 53-71, 2001.

Werner, M., Langebroek, P. M., Carlsen, T., Herold, M., and Lohmann, G.: Stable water isotopes in the ECHAM5 general circulation model: toward high-resolution isotope model- 
ing on a global scale, J. Geophys. Res.-Atmos., 116, D15109, https://doi.org/10.1029/2011JD015681, 2011.

Winstrup, M., Vallelonga, P., Kjær, H. A., Fudge, T. J., Lee, J. E., Riis, M. H., Edwards, R., Bertler, N. A. N., Blunier, T., Brook, E. J., Buizert, C., Ciobanu, G., Conway, H., Dahl-Jensen, D., Ellis, A., Emanuelsson, B. D., Keller, E. D., Kurbatov, A., Mayewski, P., Neff, P. D., Pyne, R., Simonsen, M. F., Svensson, A., Tuohy, A., Waddington, E., and Wheatley, S.: A 2700year annual timescale and accumulation history for an ice core from Roosevelt Island, West Antarctica, Clim. Past Discuss., https://doi.org/10.5194/cp-2017-101, in review, 2017.
York, D., Evensen, N. M., Lopez Martinez, M., and De Basabe Delgado, J.: Unified equations for the slope, intercept, and standard errors of the best straight line, Am. J. Phys., 72, 367-375, 2004. 